\title{
Therapeutic Potential of Heme Oxygenase-1/Carbon Monoxide in Lung Disease
}

\author{
Myrna Constantin, ${ }^{1}$ Alexander J. S. Choi, ${ }^{2}$ Suzanne M. Cloonan, ${ }^{3}$ and Stefan W. Ryter ${ }^{1,3}$ \\ ${ }^{1}$ Lovelace Respiratory Research Institute, Albuquerque, NM 87108, USA \\ ${ }^{2}$ College of Arts and Sciences, Boston College, 140 Commonwealth Avenue, Chestnut Hill, MA 02467, USA \\ ${ }^{3}$ Pulmonary and Critical Care Medicine Division, Department of Medicine, Brigham and Women's Hospital, Harvard Medical School, \\ 75 Francis Street, Boston, MA 02115, USA
}

Correspondence should be addressed to Stefan W. Ryter, sryter@partners.org

Received 14 August 2011; Accepted 6 October 2011

Academic Editor: David E. Stec

Copyright ( $) 2012$ Myrna Constantin et al. This is an open access article distributed under the Creative Commons Attribution License, which permits unrestricted use, distribution, and reproduction in any medium, provided the original work is properly cited.

\begin{abstract}
Heme oxygenase (HO), a catabolic enzyme, provides the rate-limiting step in the oxidative breakdown of heme, to generate carbon monoxide (CO), iron, and biliverdin-IX $\alpha$. Induction of the inducible form, $\mathrm{HO}-1$, in tissues is generally regarded as a protective mechanism. Over the last decade, considerable progress has been made in defining the therapeutic potential of HO- 1 in a number of preclinical models of lung tissue injury and disease. Likewise, tissue-protective effects of CO, when applied at low concentration, have been observed in many of these models. Recent studies have expanded this concept to include chemical CO-releasing molecules (CORMs). Collectively, salutary effects of the HO-1/CO system have been demonstrated in lung inflammation/acute lung injury, lung and vascular transplantation, sepsis, and pulmonary hypertension models. The beneficial effects of HO-1/CO are conveyed in part through the inhibition or modulation of inflammatory, apoptotic, and proliferative processes. Recent advances, however, suggest that the regulation of autophagy and the preservation of mitochondrial homeostasis may serve as additional candidate mechanisms. Further preclinical and clinical trials are needed to ascertain the therapeutic potential of HO-1/CO in human clinical disease.
\end{abstract}

\section{Introduction}

Stress-inducible protein systems represent a common and ubiquitous strategy that eukaryotic cells and tissues employ to maintain cellular homeostasis in adverse environments. Of these, the heat shock proteins (HSPs), whose synthesis increases with heat stress, and whose accumulation in turn confers survival advantage to cells undergoing heat stress, were among the first to be identified [1-3]. HSPs act as protein chaperones which play multifunctional roles in protein trafficking and in the clearance of denatured protein aggregates [3]. Although not strictly heat inducible in all cell types, the increased expression of a low-molecularweight stress protein $(32-34 \mathrm{kDa})$ has emerged as a general response to chemical and physical stress in cultured cells [46]. Although the agents that induce this response belong to seemingly disparate chemical and physical classes, a common feature is their potential to evoke cellular oxidative stress (i.e., altered redox homeostasis), and/or to stimulate the inflammatory response [4-10]. The $32-34 \mathrm{kDa}$ protein was identified as identical to heme oxygenase-1 [4], (HO, E.C. 1.14.99.3), a catabolic enzyme, which provides the ratelimiting step in the oxidative breakdown of heme. In the presence of $\mathrm{O}_{2}$ and the electron donor, NADPH: cytochrome p450 reductase, $\mathrm{HO}$ converts heme to biliverdin-IX $\alpha$, which is then converted to bilirubin-IX $\alpha$ by biliverdin reductase [11] (Figure 1). Additionally, ferrous iron and carbon monoxide (CO) are released during heme degradation [11].

The lung represents a critical organ for toxicological studies, since it provides essential life-sustaining functions in the transfer of molecular oxygen $\left(\mathrm{O}_{2}\right)$ to the circulatory system for ultimate use in respiration and energy generation, and at the same time can act as a major portal of entry for xenobiotic and pathogen exposure [12]. The expression of 


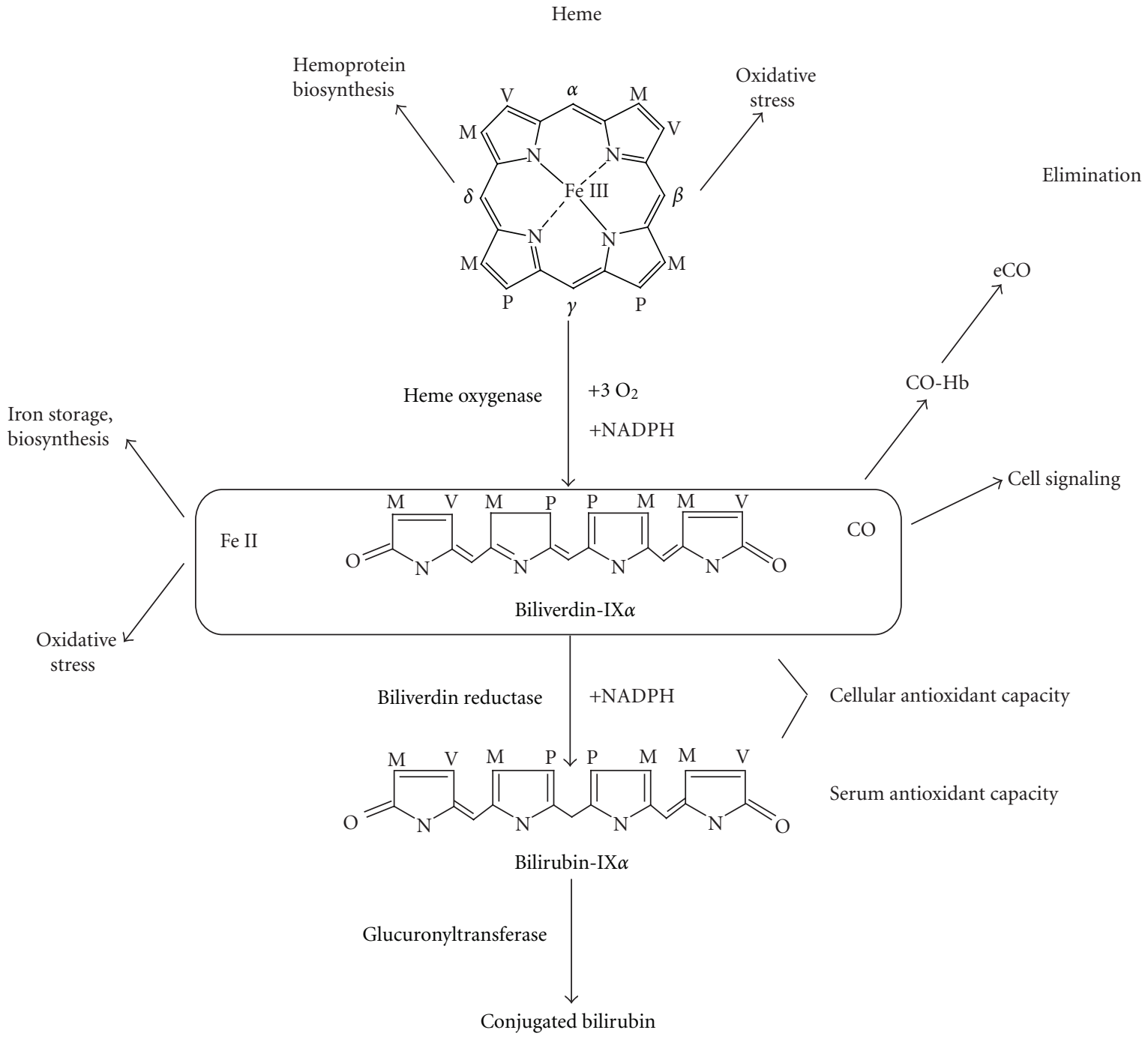

Elimination

Figure 1: The heme oxygenase reaction. Heme oxygenase-1 catalyzes the rate-limiting step in heme degradation. The reaction produces biliverdin-IX $\alpha$, carbon monoxide (CO), and ferrous iron (Fe II), at the expense of molecular oxygen and NADPH. Biliverdin-IX $\alpha$ produced in the $\mathrm{HO}$ reaction is then converted to bilirubin-IX $\alpha$ by biliverdin reductase. (Side chains are labeled as M: methyl, V: vinyl, P: propionate). The reactants and products of these enzymatic reactions have numerous and diverse biological sequelae. Heme is a vital molecule used in biosynthesis of cytochromes and other hemoproteins. Accumulation of this metabolite may promote deleterious oxidative reactions. Biliverdin-IX $\alpha$ and bilirubin-IX $\alpha$ may serve as cellular antioxidants, whereas circulating bilirubin may also provide antioxidant benefit in plasma. Bilirubin-IX $\alpha$ is conjugated by hepatic glucuronyltransferases and secreted by the biliary fecal route. CO has numerous signal transduction effects as outlined in this review. Systemic CO forms bind hemoglobin to form carboxyhemoglobin (CO-Hb). CO eventually diffuses to the lung where it is eliminated as exhaled CO (eCO). Fe (II) represents a potentially toxic metabolite of heme degradation. A potential metabolic fate of the released iron is sequestration by the iron storage protein ferritin.

HO-1 is now believed to act as a general protective mechanism of the lung in response to stress stimuli, especially those involving oxidative or inflammatory components [13-16].

HO-1 has in recent years been demonstrated to confer protection in a number of preclinical animal models of tissue injury and disease [13-20] (reviewed in [21]). This review will highlight those aspects of $\mathrm{HO}-1$ tissue protection relevant to lung disease. Furthermore, accumulating studies over the past decade have shown that the exogenous application of the HO-1 end-product $\mathrm{CO}$, when administered at low concentrations, or alternatively, by pharmacological application of carbon-releasing molecules (CORMs), can also confer protective effects in models of inflammatory stress or tissue injury [22-24] (reviewed in [21, 25]). Tissue protection has also been described for the exogenous application of bile pigments, biliverdin-IX $\alpha$, and bilirubin-IX $\alpha$, which represent the end products of the heme degradation pathway [26-28].

Many of the studies concerning $\mathrm{HO}-1 / \mathrm{CO}$-dependent cytoprotection cite mechanisms involve the modulation of the inflammatory response, including, but not limited to, 


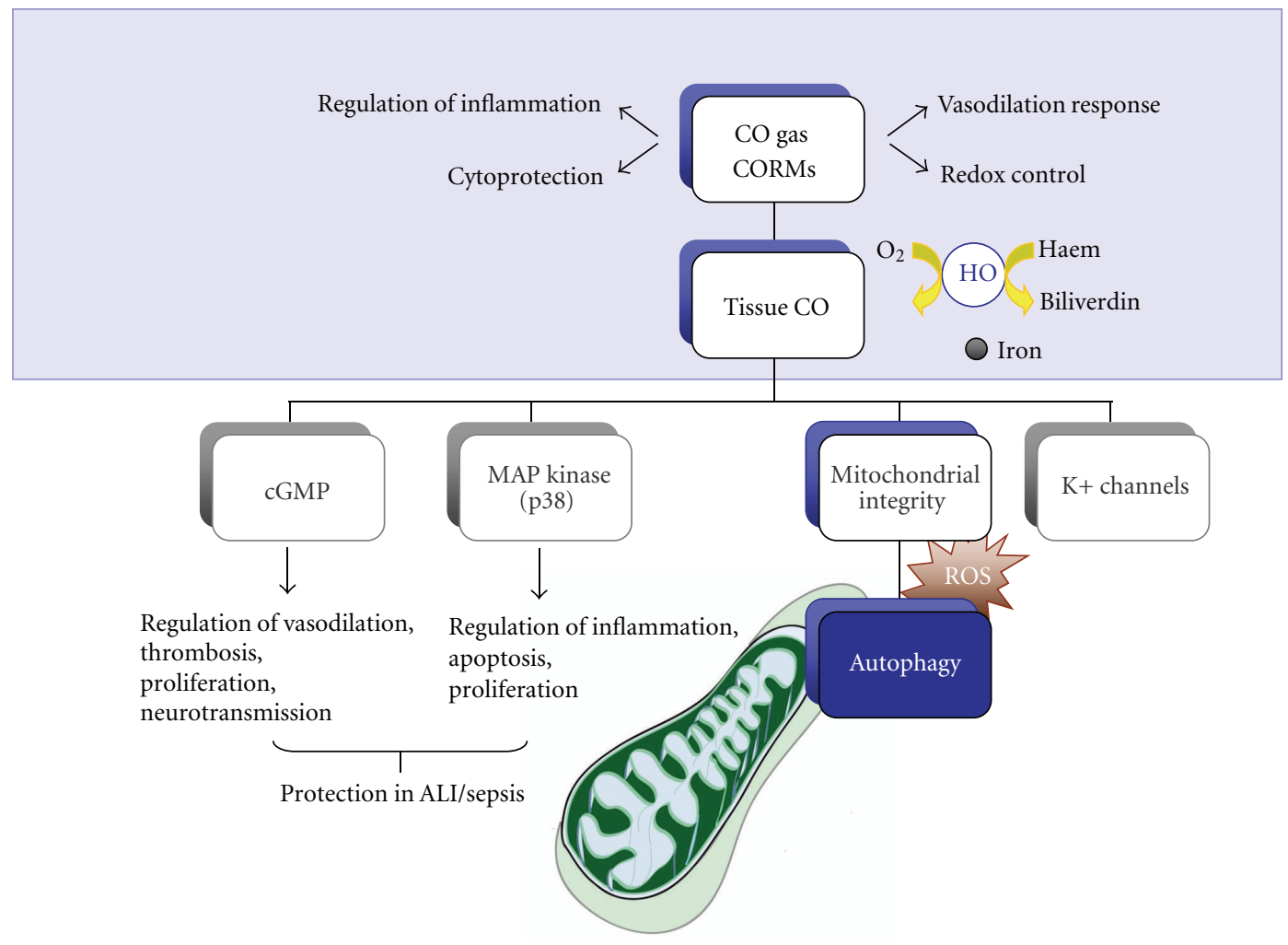

Figure 2: Overview of the signaling pathways relevant to the cytoprotective effects of CO. HO-1 and CO can confer cyto-/tissueprotection in models of acute lung injury (ALI) and sepsis. The homeostatic and beneficial effects of CO gas and CO-releasing molecules (CORMs) in animal models of ALI/sepsis occur through multiple cellular and molecular mechanisms that include regulation of the redox state, inflammation, the vasodilation response. CO gas and CORMs regulate different signaling pathways including cyclic guanosine monophosphate (cGMP), mitogen-activated protein (MAP), kinase signaling pathways, and potassium $\left(\mathrm{K}^{+}\right)$ion channels. Autophagy is regulated by $\mathrm{HO}-1 / \mathrm{CO}$ levels in a cell-type-specific manner and has a role in the maintenance of mitochondrial integrity and modulation of reaction oxygen species (ROS) production.

downregulation of proinflammatory cytokine(s) production $[22,23]$, as well as the modulation of programmed cell death (i.e., apoptosis) [29, 30], and cell proliferation [31-34], depending on cell type and experimental context (Figure 2). More recent studies, as outlined in this review, suggest additional novel candidate mechanisms for CO-dependent protection, including the regulation of cellular macroautophagy, the maintenance of mitochondrial integrity, and mitochondrial biogenesis. This review will summarize recent findings on the role of $\mathrm{HO}-1 / \mathrm{CO}$ in lung injury and pulmonary disease, with an emphasis on disease pathogenesis and potential therapeutic applications.

1.1. The Heme Oxygenase Enzyme System. The microsomal enzyme heme oxygenase (HO, E.C. 1:14:99:3) exerts a vital metabolic function in the regulation of cellular and tissue heme homeostasis and consequently affects intracellular and tissue iron distribution [35]. The HO enzyme was originally discovered (ca. 1968-1969) as an NADPHdependent enzymatic activity present in hepatic microsomal membrane preparations that is responsible for heme degradation [11]. HO is distinct from cytochrome p450, the major hepatic microsomal drug- and steroid-metabolizing system [36]. The two systems share some common features, including a requirement for electron mobilization from the reductase component of cytochrome p450 [37-40]. Similar to cytochrome $\mathrm{p} 450$, the $\mathrm{HO}$ enzyme reaction utilizes an activated oxygen molecule $\left(\mathrm{O}_{2}\right)$ bound to the ferrous iron of a heme coenzyme to catalyze substrate oxidation [38]. In contrast, p450 oxidizes a bound substrate (steroid or xenobiotic compound) [37], whereas HO specifically degrades heme $[11,41,42]$. The association of heme with the $\mathrm{HO}$ enzyme is transient, such that the bound heme uniquely serves as both catalytic cofactor, and substrate $[11,41,42]$.

$\mathrm{HO}$ catalyzes the selective ring opening of heme at the $\alpha$ methane bridge carbon to form the open chain tetrapyrrole biliverdin-IX $\alpha$. The reaction proceeds through three oxidation cycles, requiring three moles of $\mathrm{O}_{2}$ per heme oxidized $[11,43]$. In each oxidation cycle, electrons from NADPH are utilized to reduce the heme iron to the ferrous form, which is permissive of $\mathrm{O}_{2}$ binding, and subsequently, to activate the bound $\mathrm{O}_{2}$ [43]. For each molecule of heme oxidized, one mole each of ferrous iron and carbon monoxide (CO) are also released [11]. In catalyzing the breakdown of heme, $\mathrm{HO}$ provides the major source of endogenous biological CO production [11]. The HO reaction, which is rate limiting for the pathway, is generally regarded as a detoxification reaction, in that heme, a potentially deleterious prooxidant 
is processed for subsequent elimination steps. The cytosolic enzyme, $\mathrm{NAD}(\mathrm{P}) \mathrm{H}$ : biliverdin reductase, reduces biliverdinIX $\alpha$ to the hydrophobic pigment bilirubin-IX $\alpha$ [44]. Bilirubin IX $\alpha$ accumulates in serum, where it circulates in a protein-bound form, and acts as a physiological antioxidant $[45,46]$. Circulating bilirubin IX $\alpha$ is conjugated to watersoluble glucuronide derivatives by hepatic microsomal phase II enzymes and then subsequently eliminated through the bile and feces [47].

1.2. HO Isozymes. HO can exist in two distinct isozymes: the inducible form, heme oxygenase-1 (HO-1), and the constitutively expressed isozyme, heme oxygenase-2 (HO2) [48]. The inducible isozyme $\mathrm{HO}-1$ is a ubiquitous mammalian shock protein (identified by molecular-cloning strategies as identical to the major $32 \mathrm{kDa}$ mammalian stress inducible protein) [4]. HO-1 is regulated at the transcriptional level by environmental stress agents. The myriad of inducing conditions that elicit this response is not limited to xenobiotic exposure (i.e., heavy metals, sulfhydryl reactive substances, oxidants) but also includes endogenous mediators (i.e., prostaglandins, nitric oxide, cytokines, heme), physical or mechanical stresses (i.e., shear stress, ultravioletA radiation), and extremes in $\mathrm{O}_{2}$ availability (hyperoxia or hypoxia), as reviewed in $[21,49]$. The induction of HO-1 occurs as a general response to oxidative stress $[4,5,50]$. High levels of HO-1 expression occur in the spleen and other tissues responsible in the degradation of senescent red blood cells $[11,51]$. With the exception of these tissues, $\mathrm{HO}-1$ expression is generally low in systemic tissues in the absence of stress. Furthermore, the induction of HO-1 is a common response to elevated temperature in rat organs [52].

The constitutively expressed form, $\mathrm{HO}-2$, is expressed abundantly in the nervous and cardiovascular systems [16]. $\mathrm{HO}-2$ catalyzes the identical biochemical reaction as HO-1 but represents a product of a distinct gene and differs from HO-1 in primary structure, molecular weight, and kinetic parameters [53, 54]. HO-2 contains additional noncatalytic heme-binding domains which are not present in HO-1 [55]. The transcriptional regulation of HO-2 is typically refractory to most inducing agents with the exception of glucocorticoids, which stimulate $\mathrm{HO}-2$ transcription in the nervous tissue $[56,57]$.

1.3. Heme Oxygenase-1: A Cytoprotective Molecule. It is now well established in cell culture and animal studies that HO1 expression provides a general cyto- and tissue-protective effect, which is elicited as a generalized protective response to environmental derangements. From published studies, it is generally concluded that HO-1 can defend against oxidative stress conditions in vitro and in vivo by modulating apoptotic and inflammatory pathways [13, 18, 22, 58, 59]. However, the molecular processes and mechanisms, in which HO- 1 provides cellular and tissue protection, remain only partially understood. The direct removal of heme may serve an antioxidative function, since heme acts as a prooxidant compound on the basis of its iron functional group $[60,61]$. Hypothetically, a buildup of heme from the denaturation of cellular hemoproteins, or from the impaired biosynthesis or assembly of hemoproteins, may result in oxidative stress to the cell, through the promotion of iron-dependent free radical reactions (i.e., Fenton reaction). However, the extent to which the "free" heme pool is mobilized during stress remains unknown. Heme is well known as a lipid peroxidation catalyst in model systems $[60,61]$ and may cause endothelial cell injury [62]. By breaking down heme, HO liberates heme iron, which can itself represent a deleterious catalytic byproduct with excessive overexpression [63]. HOderived iron has been shown to drive the synthesis of ferritin, which serves as a protective sink for intracellular redoxactive iron [64]. In addition to iron, the reaction products of the $\mathrm{HO}$ system, namely, biliverdin/bilirubin, and $\mathrm{CO}$ may also contribute to cytoprotection. Evidence for this is based largely on exogenous or pharmacological application of $\mathrm{CO}$ or biliverdin/bilirubin as described in detail in the sections below, and it remains incompletely clear whether these mechanisms can account entirely for the cytoprotective properties of the natural enzyme. An emerging consensus is that the pleiotropic effects of HO-1 summarized by the collective effects of the generation and distribution of bioactive products and their downstream sequelae collectively contribute to $\mathrm{HO}$-dependent cytoprotection. In this regard, HO-2 likely also serves as a protective agent against oxidative stress by reducing intracellular heme concentrations and by increasing levels of bilirubin and ferritin, both of which are potent antioxidants [56]. However, HO-2 does not typically respond to transcriptional activation via environmental stimuli, although some posttranscriptional modulation of expression has been described $[57,65]$.

The critical role of HO-1 in systemic homeostasis was illustrated in the only documented case of HO-1 deficiency in a human subject, who presented with extensive endothelial cell damage, anemia, and abnormal tissue iron accumulation [66]. In addition, knockout mice with the $H m o x 1^{-/-}$genotype revealed hepatic and renal iron deposition, anemia and increased vulnerability to oxidative stress [35, 67].

1.4. Biliverdin/Bilirubin Mediators of HO-Dependent Cytoprotection. The cytoprotective effects of $\mathrm{HO}-1$ have been postulated to involve the generation of its end products. The openchain tetrapyrroles biliverdin and bilirubin exert antioxidant properties in vitro $[45,46]$, which have been demonstrated to confer cytoprotective and antiproliferative properties [27, 28, 68, 69] (reviewed in [70, 71]). Increasing evidence suggests that bilirubin plays an important physiological role as an antioxidant in serum $[38,39]$. Increases of serum BR have been correlated with vascular protection and resistance to oxidative stress in vivo [72]. Hyperbilirubinemic Gunn rats display reduced plasma biomarkers of oxidative stress following exposure to hyperoxia, relative to normal controls, suggesting that hyperbilirubinemia may confer protection against oxidative stress [72]. Recent clinical studies indicate a relationship between circulating bilirubin levels and risk of vascular disease. Serum BR levels were indicated as an independent, inverse risk factor for coronary artery disease and peripheral vascular disease $[73,74]$. In a large-scale prospective study of men, subjects in the midrange of serum 
BR concentration were at the lowest incidence of ischemic heart disease relative to those subjects displaying the lowest or highest fifth of serum BR distribution [75]. In healthy subjects, serum BR levels were inversely correlated with two indicators for atherosclerosis [76]. Patients with Gilbert's syndrome, who have increased levels of circulating unconjugated bilirubin due to reduced glucuronyltransferase activity, displayed reduced incidence of ischemic heart disease when compared to the general population [77]. Serum samples from Gilbert's patients were further shown to have increased antioxidant capacity and resistance to oxidation [78]. It should be noted that bilirubin also may exert toxicological consequences at supraphysiological levels, as implicated in the neurological injury associated with neonatal jaundice [79].

\section{Protective Effects of $\mathrm{HO}-\mathbf{1} / \mathrm{CO}$ in Lung Injury and Disease}

2.1. HO-1/CO in Endotoxemia and Sepsis. HO-1, as an inducible cytoprotective molecule, has been implicated as a modulator of the acute inflammatory response, as demonstrated using in vitro and in vivo models of inflammatory stress [14, 15,22 ]. HO-1 gene expression via adenovirus-mediated gene delivery inhibited the bacterial lipopolysaccharide- (LPS-) induced production of pro-inflammatory cytokines, such as tumor necrosis factor- $\alpha$ (TNF- $\alpha$ ), interleukin- $1 \beta$ (IL- $1 \beta$ ), interleukin-6 (IL-6), and macrophage inflammatory protein$1 \beta$ (MIP- $1 \beta$ ) in cultured macrophages in vitro, and increased the anti-inflammatory cytokine interleukin-10 (IL-10) levels during LPS challenge [22].

HO-1 has also exhibited anti-inflammatory effects through in vivo models of inflammatory diseases. Additional studies have shown that enhanced gene expression of HO1 in rat lungs via intratracheal adenoviral-mediated gene transfer limited murine acute lung injury following influenza virus infection [14] and ameliorated LPS-induced lung injury in mice via increased IL-10 production $[15,22]$. Furthermore, administration of biliverdin, a direct product of $\mathrm{HO}$ degradation, resulted in a significant decrease of proinflammatory cytokines, such as IL-6, upregulation of IL-10 levels, and reduction of lung injury markers in LPStreated rats. Thus, biliverdin protected against systemic inflammation and lung injury after lethal exposure to LPS. This defense against LPS-induced injury applied to cultured lung endothelial cells as well as macrophages [80]. HO-1 has also displayed anti-inflammatory effects in various models of tissue injury besides the lung, which include enhanced protection during cardiac [81], renal [82], and liver [83] transplantation.

Several recent studies have implicated a protective role for HO-1 during microbial sepsis [84-87]. Using the cecal ligation and puncture (CLP) technique to induce sepsis, HO-1-deficient mice $\left(H \operatorname{mox} 1^{-/-}\right)$suffered higher mortality rates compared with $\mathrm{HO}-1$ sufficient mice. These mice were also shown to have an increased level of free circulating heme rendering them more susceptible to death from sepsis [85].
Conversely, targeted overexpression of $\mathrm{HO}-1$ to smooth muscle cells and myofibroblasts, and bowel protected against sepsis-induced mortality associated with Enterococcus faecalis infection, enhanced bacterial clearance by increasing phagocytosis and the endogenous antimicrobial response [84].

High-mobility group box-1 (HMGB1) protein can mediate various cellular responses, including chemotaxis and accumulation of proinflammatory cytokines. Thus, this molecule may represent a key target in strategies to limit inflammation. With respect to potential mechanisms for HO-1-mediated protection in sepsis, several studies have demonstrated that circulating levels of HMGB1 contribute to LPS-induced mortality in $\operatorname{Hmox}^{-/-}$mice $[86,87]$. Furthermore, the pharmacological administration of $\mathrm{HO}$ 1-inducing compounds (i.e., heme) significantly reduced plasma levels of HMGB1 in mice challenged with LPS or CLP, which was also associated with the reduction of serum TNF- $\alpha$, and IL- $1 \beta$ levels $[86,87]$. Transfection of HO-1 or induction of $\mathrm{HO}-1$-derived $\mathrm{CO}$ resulted in a significant reduction in the translocation and release of high-mobility group box 1 (HMGB1) in CLP-induced sepsis in vivo. In conclusion, $\mathrm{HO}-1$-derived $\mathrm{CO}$ significantly attenuated HMGB1 release during sepsis, and this inhibition is a necessary step of CO in protection against sepsis [87].

In vitro experiments showed that pretreatment with $\mathrm{HO}-$ 1 inducers, or transfection of HO-1, significantly inhibited HMGB1 release, translocation of HMGB1 from nucleus to cytosol, and release of proinflammatory cytokines (i.e., TNF$\alpha$, IL- $1 \beta$, and IFN- $\beta$ ) in RAW264.7 cells stimulated with LPS. These effects were mimicked by $\mathrm{CO}$ donor compounds and reversed by CO scavengers [87]. Thus, inhibition of HMGB1 release via $\mathrm{HO}-1$ treatment may represent a potential application for therapeutic intervention against sepsis [87].

Hemin administration was shown to protect mice from lethal endotoxemia and sepsis induced by LPS or CLP, respectively [87]. In this context, heme administration was used as a pharmacological agent to induce HO-1 in healthy animals before applying sepsis. In contrast however, a recent study has suggested that heme-driven tissue damage contributes to the pathogenesis of severe sepsis. The authors demonstrate that the exacerbated mortality of $H \operatorname{mox} 1^{-/-}$ mice subjected to low-grade polymicrobial infection induced by CLP correlated with the accumulation of free heme in the plasma. Administration of free heme to wild-type $\left(H m o x 1^{+/+}\right)$mice subjected to low-grade microbial infection (nonlethal) was sufficient to elicit a lethal form of severe sepsis. The development of lethal forms of severe sepsis after high-grade infection was associated with reduced serum concentrations of the heme-sequestering protein hemopexin (HPX), a protein produced by the body to scavenge free heme, whereas HPX administration after high-grade infection prevented tissue damage and lethality. Further, the lethal outcome of septic shock in patients was associated with reduced levels of serum HPX concentrations, suggesting that targeting free heme by modulation of HPX might be used therapeutically to treat severe sepsis. Therefore, in a clinical setting, monitoring the patients' levels of circulating heme and/or HPX might be used to predict the likelihood of a fatal outcome in each case of severe sepsis [85]. 
$\mathrm{CO}$ also plays a role in the protection against lung inflammation and injury in rodents. In mice, low doses of $\mathrm{CO}$ (250 ppm), as well as HO-1 expression, when administered with a sublethal dose of LPS, selectively inhibited the expression of LPS-induced proinflammatory cytokines including TNF $\alpha$, IL- $1 \beta$, and MIP- $1 \beta$ [22]. CO dose-dependently increased LPS-inducible IL-10 [22]. Similar effects were observed in cultured macrophages exposed to $\mathrm{CO}$ [22]. The p38 mitogen-activated protein kinase (MAPK) pathway was shown to be important for the CO-mediated effect in these cells [22].

The anti-inflammatory protection against LPS-induced organ injury conferred by $\mathrm{CO}$ was also observed in association with inhibition of inducible nitric oxide synthase (iNOS) expression and activity in the lung. In contrast, while CO also protected against LPS-induced hepatic injury, an enhancement of iNOS expression and activity by $\mathrm{CO}$ was observed in this organ [88]. Studies of primary lung macrophages and hepatocytes in vitro revealed a similar effect; CO inhibited LPS-induced cytokine production in lung macrophages while reducing LPS-induced iNOS expression, and protected hepatocytes from apoptosis while augmenting iNOS expression [88]. It remains unclear to which extent these changes in iNOS contribute to the cytoprotection conferred by $\mathrm{CO}$, as it appears that the functional consequences of iNOS regulation by CO differ in an organ-specific fashion.

Anti-inflammatory effects of $\mathrm{CO}$ were also recently demonstrated in a swine model of endotoxin challenge. $\mathrm{CO}$ reduced the development of disseminated intravascular coagulation and diminished serum levels of the proinflammatory IL- $1 \beta$ in response to LPS and induced IL-10 after LPS challenge [89]. Recent studies evaluated the efficacy of inhaled CO in reducing LPS-induced lung inflammation in cynomolgus macaques (a nonhuman primate model). CO exposure (500 ppm, $6 \mathrm{~h}$ ) following LPS inhalation decreased TNF- $\alpha$ release in the bronchioalveolar lavage fluid (BALF) but did not affect IL-6 and IL-8 release, in addition to reducing pulmonary neutrophilia (not observed at lower concentrations of $\mathrm{CO}$ ). This reduction of pulmonary neutrophilia was as efficacious as pretreatment with a wellcharacterized inhaled corticosteroid. However, the therapeutic efficacy of $\mathrm{CO}$ required relatively high doses that resulted in high carboxyhemoglobin $(\mathrm{CO}-\mathrm{Hb})$ levels $(>30 \%)$. This work highlights the complexity of interspecies variation of dose-response relationships of $\mathrm{CO}$ to $\mathrm{CO}-\mathrm{Hb}$ levels and to the anti-inflammatory functions of CO [90]. This study is the first to examine the therapeutic index and dose-response relationships of CO therapy in nonhuman primates, and this warrants further investigations in humans [90].

2.2. HO-1/CO in High Oxygen Stress. $\mathrm{O}_{2}$ is required to sustain aerobic life, but paradoxically, due to its biradical nature and reactivity, and consequently its ability to participate in electron transfer reactions, can also be harmful to life [91]. Supraphysiological concentrations of $\mathrm{O}_{2}$ (hyperoxia) are routinely used in the clinic to prevent or treat hypoxemia and acute respiratory failure [92]. However, prolonged exposure to hyperoxia can result in tissue damage in many organs, including lungs, and lead to the development of both acute and chronic lung injury [92]. Hyperoxia-induced damage in mice is characterized by an alveolar-capillary barrier dysfunction, impaired gas exchange, and pulmonary edema [13, 93]. Elevated HO-1 protein expression was reported in lungs of mice and in cultured epithelial cells subjected to hyperoxia [93]. The expression of ho-1 in rat lungs by intratracheal adenoviral-mediated gene transfer, which increased HO-1 expression in the bronchiolar epithelium, protected against the development of pulmonary damage during hyperoxia exposure [13]. Rats infected with ho-1 prior to hyperoxia displayed reductions in lung injury markers, neutrophil infiltration, and apoptosis, and a marked increase in survival against hyperoxic stress when compared to control-infected rats [13]. In vitro, HO-1 overexpression also protected epithelial cells against hyperoxia-induced cytotoxicity [58].

Similarly, low doses of CO have been shown to provide protection against hyperoxic lung injury. The administration of $\mathrm{CO}(250 \mathrm{ppm})$ during hyperoxia exposure prolonged the survival of rats and mice subjected to a lethal dose of hyperoxia and dramatically reduced histological indices of lung injury, including airway neutrophil infiltration, fibrin deposition, alveolar proteinosis, pulmonary edema, and apoptosis, relative to animals exposed to hyperoxia alone $[23,94]$. In mice, hyperoxia was shown to induce the expression of proinflammatory cytokines (i.e., TNF $\alpha$, IL- $1 \beta$, IL-6) and activate major MAPK pathways in lung tissue. The protection afforded by $\mathrm{CO}$ treatment against the lethal effects of hyperoxia correlated with the inhibited release of proinflammatory cytokines in BALF. Genetic studies in mice revealed that the anti-inflammatory effect of $\mathrm{CO}$ depended on the MKK3/p38 $\beta$ MAPK pathway [94]. Corresponding in vitro studies of oxidative lung cell injury have also indicated protective effects of low-dose CO application (250 ppm). CO inhibited hyperoxia-induced apoptosis of cultured epithelial cells, which required the activation of the MKK $3 / \mathrm{p} 38 \beta$ MAPK pathway [94] as well as the STAT3 pathway [95]. Further mechanistic studies in pulmonary endothelial cells revealed that low-dose CO application inhibited the initiation and propagation of extrinsic apoptotic pathways in mouse lung endothelial cells subjected to hyperoxia [96]. CO inhibited $\mathrm{O}_{2}$-induced activation of the death inducing signal complex (DISC) and downstream activation of apoptogenic factors, including caspases $(-8,-9,-3)$ and Bid, thereby affording protection against cell death. $\mathrm{CO}$ also diminished membrane-dependent reactive oxygen species (ROS) production during hyperoxia by inhibiting the ERK1/2 MAPK pathway [96].

2.3. HO-1/CO in Ventilator-Induced Lung Injury. Mechanical ventilation is commonly used clinically for the maintenance of critically ill patients. However, this therapeutic tool can lead to the development of acute lung injury (ALI)/and acute respiratory distress syndrome (ARDS). Despite reductions in tidal volume currently implemented during mechanical ventilation in the clinic, the complications of ALI/ARDS continue to present a high rate of mortality $(\sim 40 \%)$ [ 97 , 98]. The lung damage incurred by mechanical ventilation is referred to as ventilator-induced lung injury (VILI) and 
involves a sterile inflammatory response to cyclic stretching of the tissue [99]. An anti-inflammatory effect of CO was first described in a two-hit model of VILI in which rats were subjected to an injurious high tidal volume ventilator setting combined with intraperitoneal endotoxin injection. This model caused increased expression of HO-1 in the lung. The inclusion of low-concentration CO $(250 \mathrm{ppm})$ in the ventilator circuit reduced the inflammatory cell count in BALF. In the absence of cardiovascular derangements, CO dose-dependently decreased TNF $\alpha$ and increased IL10 content in the BALF [100]. CO application was also found to confer tissue protection in a mouse model of VILI, using moderate tidal volume settings [101, 102]. In the mouse model, mechanical ventilation caused lung injury reflected by increases in protein concentration, and total cell and neutrophil counts in the BALF. CO reduced ventilation-induced cytokine and chemokine production and prevented lung injury during ventilation, as reflected by the inhibition of ventilation-induced increases in BALF protein concentration and cell count, lung neutrophil influx, and pulmonary edema formation $[101,102]$. CO also prevented the HO-1 response to mechanical ventilation, indicating a tissue-protective effect that preceded and did not necessarily depend on secondary activation of stress proteins [101]. Inclusion of CO during ventilation increased the expression of the tumor-suppressor protein caveolin1 in mouse lung epithelium. Mice genetically deficient in caveolin-1 $\left(\mathrm{Cav}_{-1} 1^{-/-}\right)$were reported to be more susceptible to VILI than their wild-type counterparts. Furthermore, CO ventilation failed to confer protection against mechanical ventilation-induced lung injury in $c a v-1^{-/-}$mice, indicating a requirement for caveolin-1 in the protective effects of $\mathrm{CO}$ [101]. Mechanical ventilation was also shown to increase the expression of the proinflammatory transcriptional regulator early growth response protein-1 (Egr-1) in the lungs of mice, which in turn was inhibited by CO ventilation. The Egr-1-1mice resisted lung injury during ventilation, relative to their wild-type counterparts, affirming that Egr-1 acts as a proinflammatory mediator in VILI [102].

In lung macrophages, peroxisome proliferator activated receptor- $\gamma$ (PPAR- $\gamma$ ), a nuclear regulator, has been demonstrated to act as an anti-inflammatory mediator by counteracting the proinflammatory effects of Egr-1 [103]. $\mathrm{CO}$ exposure was found to increase PPAR- $\gamma$ in cultured macrophages. Furthermore, chemical inhibition of PPAR$\gamma$ in vivo reversed the protective effects of $\mathrm{CO}$ in this model with respect to Egr-1 regulation and lung injury parameters [102]. These studies in VILI models are supportive of general protective effects of $\mathrm{CO}$ in the maintenance of the alveolar-capillary barrier. $\mathrm{CO}$ has also been demonstrated to inhibit alveolar fluid clearance [104], and these effects should also be further studied when implementing CO for pulmonary therapies. These studies collectively suggest that mechanical ventilation in the presence of $\mathrm{CO}$ may provide protection in animal models of VILI. Further research is needed to better understand the pathogenesis of VILI as well as the protective potential of $\mathrm{CO}$ and other so-called therapeutic gases in these models. It remains unclear whether the protective effects of these gases as observed in the mouse would ultimately translate to clinical effectiveness in humans.

2.4. HO-1/CO in Pulmonary Ischemia Reperfusion Injury and Lung Transplantation. The therapeutic potential of HO$1 / \mathrm{CO}$ in ischemia/reperfusion (I/R) injury models has been described extensively in rodent systems. Lung I/R caused by occlusion of the pulmonary artery was shown to cause lung apoptosis, as evidenced by biochemical markers including caspase activation, expression changes in $\mathrm{Bcl}_{2}$ family proteins, cleavage of PARP, and mitochondrial cytochrome-c release [105]. CO conferred tissue protection in rodents subjected to lung I/R injury, as evidenced by reduced markers of apoptosis, which depended on activation of the MKK $3 / \mathrm{p} 38 \alpha$ MAPK pathway [106]. Mechanistic studies from the same laboratory revealed that CO conferred similar antiapoptotic protection in cultured pulmonary artery endothelial cells against anoxia reoxygenation stress, which was dependent on activation of the MKK3/p38 $\alpha$ MAPK pathway [106, 107]. Additional proposed pathway mechanisms included the activation of the phosphatidylinositol-3-kinase/Akt pathway and downstream induction of the signal transducer and activator of transcription (STAT)-3 [107].

In vivo studies using homozygous ho-1 knockout mice (hmox $-1^{-/-}$) demonstrated that HO-1 deficiency conferred sensitivity to the lethal effects of lung I/R injury. Application of exogenous $\mathrm{CO}$ by inhalation compensated for the HO1 deficiency in $h m o x-1^{-/-}$mice and improved survival subsequent to pulmonary I/R [108]. The protection provided by CO involved the stimulation of fibrinolysis, by the cGMPdependent inhibition of plasminogen activator inhibitor1, a macrophage-derived activator of smooth muscle cell proliferation [108]. CO also inhibited fibrin deposition and improved circulation in ischemic lungs [109]. These protective effects were related to the inhibited expression of the proinflammatory transcription factor Egr-1, and the subsequent downregulation of Egr-1 target genes, which contribute to inflammatory or prothrombotic processes. The downregulation of Egr-1 depended on the enhancement of cGMP signaling by CO treatment, leading to the inhibition of the ERK1/2 MAPK pathway [109].

$\mathrm{I} / \mathrm{R}$ injury also represents an important causative component of graft rejection after lung transplantation. During orthotopic left lung transplantation in rats, the transplanted lungs were shown to develop severe intra-alveolar hemorrhage and intravascular coagulation. The application of continuous CO exposure (500 ppm) markedly preserved the graft and reduced hemorrhage, fibrosis, and thrombosis after transplantation. Furthermore, CO inhibited lung cell apoptosis and downregulated lung and proinflammatory cytokine and growth factor production which were induced during transplantation [110]. Additional studies revealed that protection against $\mathrm{I} / \mathrm{R}$ and inflammatory injury was reduced in syngeneic rat orthotopic lung transplantation by inhalation exposure to either the donor or the recipient [111]. Delivery of CO to lung grafts by saturation of the preservation media reduced I/R injury and inflammation in syngeneic rat orthotopic lung transplantation [112]. 
2.5. Protective Role of CO in Vascular Injury. A protective role for $\mathrm{CO}$ in vascular injury has been reported. In this study, inhaled CO prevented arteriosclerotic lesions that occur following aorta transplantation in rodent models. Exposure to a low level of CO $(250 \mathrm{ppm})$ for 1 hour before injury was sufficient to suppress intimal hyperplasia arising from balloon injury [32]. The protective effect of $\mathrm{CO}$ was associated with inhibition of graft leukocyte infiltration/activation as well as with inhibition of smooth muscle cell proliferation [32]. A more recent study has shown that intravenous injection of CO-saturated saline caused immediate vasodilation and increased blood flow in the hamster skin microcirculation, an effect that lasted up to 90 mins [113]. These changes were related to increased cardiac output and local cGMP levels. This study supports the possible use of CO-saturated solutions as a vasodilator in critical conditions; however, dosage appears to be critical, since higher and lower dosages by a factor of two were ineffective [113].

2.6. Carbon Monoxide and Pulmonary Arterial Hypertension $(\mathrm{PAH})$. Pulmonary arterial hypertension $(\mathrm{PAH})$ is a terminal disease characterized by a progressive increase in pulmonary vascular resistance leading to right ventricular failure. Several studies suggest that $\mathrm{HO}-1$ or $\mathrm{CO}$ can exert protective effects in the context of pulmonary hypertension, and reverse hypoxic pulmonary vasoconstriction. The hmox $-1^{-/-}$null mice displayed an exaggerated response to chronic hypoxia relative to wild-type mice, as exemplified by marked right heart hypertrophy, which included right ventricular infarcts and the formation of mural thrombi [114]. Chemical induction of HO-1 inhibited the development of PAH in rat lungs in response to chronic hypoxia [17]. Furthermore, transgenic mice with lung-specific overexpression of HO-1 displayed reduced lung inflammation, pulmonary hypertension, and vascular hypertrophy during chronic-hypoxia treatment, relative to wild-type mice [18]. In monocrotaline- (MCT-) induced hypertension, protective effects were observed by treatment with the antiproliferative agent rapamcyin, which were associated with the induction of HO-1 [115]. In vitro, the antiproliferative effect of rapamycin on smooth muscle cells also depended in part on $\mathrm{HO}-1$ expression, as it was diminished in smooth muscle cells derived from ho- $1^{-/-}$mice [115].

Inhalation of $\mathrm{CO}$ has been shown to attenuate the development of hypoxia-induced $\mathrm{PAH}$ in rats, by a mechanism possibly involving activation of $\mathrm{Ca}^{2+}$-activated $\mathrm{K}^{+}$ channels [116] and NO generation [34]. In hypoxia and monocrotaline-induced PAH in rodents, daily CO exposure (250 ppm, $1 \mathrm{~h}$ ) reversed established PAH and right ventricular hypertrophy and restored right ventricular and pulmonary arterial pressures. CO treatment restored pulmonary vascular architecture to a near-normal condition [34]. The protective effect of $\mathrm{CO}$ was endothelial cell dependent and associated with increased apoptosis and decreased cellular proliferation of vascular smooth muscle cells [34]. The ability of $\mathrm{CO}$ to reverse $\mathrm{PAH}$ was further shown to require endothelial nitric oxide synthase (eNOS) and NO production, as indicated by the inability of $\mathrm{CO}$ to reverse chronic hypoxia-induced PAH in $\mathrm{NOOS}^{-/-}$mice [34]. Biliverdin and bilirubin have also been shown to exert antiproliferative effects on vascular smooth muscle and thus may also have therapeutic potential in $\mathrm{PAH}$ and other diseases involving aberrant vascular cell proliferation $[27,28]$.

\section{Role of $\mathrm{HO}-1 / \mathrm{CO}$ in the Regulation of Autophagy}

In addition to classical mechanisms such as apoptosis and inflammation, several recent intriguing studies suggest that HO-1, and its byproduct CO, can possibly impact the regulation of autophagy, a vital cellular process, which may in part contribute to the cytoprotective mechanism. Macroautophagy (autophagy) is a regulated cellular pathway for the turnover of organelles and proteins by lysosomal-dependent processing. The autophagy mechanism involves doublemembrane vesicles, called autophagosomes or autophagic vacuoles, that target and engulf cytosolic material, which may include damaged organelles or denatured proteins. The autophagosomes fuse with lysosomes to form singlemembrane autolysosomes. Lysosomal enzymes facilitate a degradation process to regenerate metabolic precursor molecules (i.e., amino acids, fatty acids), which can be used for anabolic pathways and ATP production [117124]. This process may thereby prolong cellular survival during starvation. During infection, autophagy assists in the immune response by providing a mechanism for the intracellular degradation of invading pathogens, such as bacteria, and may also contribute to adaptive immune mechanisms [123]. At least 30 autophagy-related (Atg) genes have been determined, primarily in yeast. The homologues of many of these Atg genes have been shown to participate in the regulation of autophagy $[125,126]$. Among these, Beclin 1 (the mammalian homolog of yeast Atg6) represents a major autophagic regulator [126]. Beclin 1 associates with a macromolecular complex that includes the class III phosphatidylinositol-3 kinase (Vps34). The Beclin 1 complex produces phosphatidylinositol-3-phosphate, a second messenger that regulates autophagosomal nucleation [124, 125]. The microtubule-associated protein-1 light chain-3B (LC3B), the mammalian homologue of Atg8 is an important mediator of autophagosome formation, which is found in association with the autophagosomal membrane [127].

Autophagy has been shown to be both protective and injurious in a variety of different models, suggesting that its role in human diseases is complex. Autophagy is generally considered to be protective when it is induced in response to stress, reducing the activation of lethal signal transduction cascades, and maintaining crucial levels of ATP that allow for the generation of proteins and other biosynthetic reactions. Autophagy also facilitates the elimination of potentially toxic protein aggregates, helping to limit the accumulation of ubiquitinylated proteins that otherwise would inhibit proteasome function. Induction of autophagy affects the progression of the cell cycle (and vice versa), suggesting that autophagy can influence cellular sensitivity to cell cycledependent toxins [128]. 
Autophagy is rarely considered a suicidal mechanism as it usually precedes apoptosis or necrosis [128]. Nevertheless, autophagy has been proposed to contribute to Type-II programmed cell death (PCD), a morphologically distinct form of PCD that involves excess levels of cellular autophagy, degradation of irreversibly damaged organelles, and preservation of cytoskeletal elements. Autophagic cell death occurs during development, in a number of homeostatic processes in adulthood that require the elimination of large amounts of cells, and during the neonatal period in order to maintain cellular energy homeostasis and survival [129]. However, there is still no conclusive evidence that a specific mechanism of autophagic cell death exists, as this phenomenon seems to occur only in cells that cannot die by conventional apoptotic mechanisms [130]. Apoptosis can occur at the same time as autophagy in the same cells suggesting a common regulatory mechanism; however, the precise crosstalk between these two processes remains to be elucidated. Several proapoptotic signaling molecules known to induce autophagy include TRAIL [131], TNF [132], FADD, DRP-I (dynamin-related protein-1), and DAPK (death-associated protein kinase) [133]. $\mathrm{Ca}^{2+}$ is a major intracellular second messenger involved in mediating both apoptosis and autophagy, where elevated $\mathrm{Ca}^{2+}$ induces autophagy which can be inhibited by ER-associated Bcl-2 [134]. The Bcl-2 proteins are also known to be important in both autophagy and apoptosis signaling. Beclin 1 has been shown to interact with Bcl-2 resulting in the inhibition of Beclin 1-mediated autophagy in response to starvation $[135,136]$. Further evidence for a cross-talk between apoptosis and autophagy is also supported by a recent study on Atg5. A truncated form of Atg5 (cleaved by calpains 1 and 2) participates in apoptosis regulation and translocates from the cytosol to mitochondria to trigger cytochrome c release and caspase activation [134]. This Atg5 fragment has been shown to bind to $\mathrm{Bcl}-\mathrm{X}_{\mathrm{L}}$, displacing $\mathrm{Bcl}-\mathrm{X}_{\mathrm{L}}-\mathrm{Bax}$ complexes, to inactivate $\mathrm{Bcl}-\mathrm{X}_{\mathrm{L}}$ antiapoptotic activity, thereby promoting Bax-Bax complex formation, which suggests that Atg5 may be an independent key player in both apoptosis and autophagy. Functional mitochondria are also needed for autophagic induction [137]. Mitochondria have been proposed to act as a platform for controlling the crosstalk between stress responses, autophagy, and programmed cell death, however, the exact mechanisms through which autophagy can intercept lethal signaling remain unknown.

The role of autophagy, whether protective or deleterious, in human diseases, or specifically in chronic lung disease remains obscure. Recently, we demonstrated a pivotal role for autophagy in cigarette smoke-induced apoptosis and emphysema. We have observed increased autophagy in mouse lungs subjected to chronic cigarette smoke exposure, and in pulmonary epithelial cells exposed to cigarette smoke extract (CSE). Knockdown of autophagic proteins inhibited apoptosis in response to cigarette smoke exposure in vitro, suggesting that increased autophagy was associated with epithelial cell death. We have also observed increased morphological and biochemical markers of autophagy in human lung specimens from patients with chronic COPD, suggestive of novel therapeutic targets for COPD treatment [138].
HO-1 has been associated with both the cytoprotective and cytotoxic functions of autophagy induction (Figure 3 ). HO-1 induces a cytoprotective role for autophagy in lung epithelial cells in response to cigarette smoke by downregulating apoptosis and autophagy-related signaling [139]. CSE increased the processing of LC3B-I to LC3B-II (the lipidated active form), within $1 \mathrm{hr}$ of exposure in Beas-2B cells. Increased LC3B-II was associated with increased autophagic activity, since inhibitors of lysosomal proteases and of autophagosome-lysosome fusion further increased LC3BII levels during CSE exposure. CSE concurrently induced extrinsic apoptosis in Beas-2B cells involving early activation of death-inducing-signaling-complex (DISC) formation and downstream activation of caspases $(-8,-9,-3)$. HO1 protected against such CSE-induced effects; adenoviralmediated expression of HO-1 inhibited DISC formation and caspase-3/9 activation in CSE-treated epithelial cells, diminished the expression of Beclin 1, and partially inhibited the processing of LC3B-I to LC3B-II. These studies were the first to demonstrate a relationship between autophagic and apoptogenic signaling in CSE-induced cell death, and their coordinated downregulation by HO-1 [139].

We have also shown that HO-1 mRNA expression was elevated in the lungs of mice chronically exposed to cigarette smoke [139], implying that $\mathrm{HO}-1$ is upregulated in response to cigarette smoke. In addition, HO-1 was shown to localise to mitochondria in response to hemin, lipopolysaccharide, and CSE in human alveolar (A549), or bronchial epithelial cells (Beas-2B) [140]. These studies suggest that the intracellular location of $\mathrm{HO}-1$, in this case, translocation to the mitochondria may be important for its role in remediating cellular stress and cell death.

In other models, HO-1 has been shown to upregulate autophagy in hepatocytes, leading to protection against hepatocyte cell death and hepatic injury from infectioninduced sepsis in mice [141]. HO-1 and autophagy are both upregulated in the liver in response to sepsis and LPS and have been shown to limit cell death. Pharmacological inhibition of HO-1 activity or knockdown of HO-1 prevents the induction of autophagic signaling in this model and resulted in increased hepatocellular injury, apoptosis, and death [141]. Finally, HO-1 dependent autophagic signaling has also been shown to have anti-inflammatory effects in LPS-stimulated macrophages where HO-1 and autophagy collectively serve to limit cytokine production [142]. HO1 is integral to regulating and dampening the inflammatory response, as demonstrated by the expressed proinflammatory phenotype found in HO-1 knockout mice. Many of the anti-inflammatory effects of HO-1 have been attributed to $\mathrm{CO}$ which, when provided exogenously, is known to decrease inflammation in macrophages and other cells.

On the contrary, HO-1 has been shown to promote autophagy and consequent cell death in a number of models. HO-1 overexpression results in the activation of mitochondrial-selective autophagy (mitophagy) resulting in the accumulation of iron-laden cytoplasmic inclusions [143] in Alzheimer's disease and Parkinson's disease. HO-1 has also been implicated in the inhibition of autophagosome 


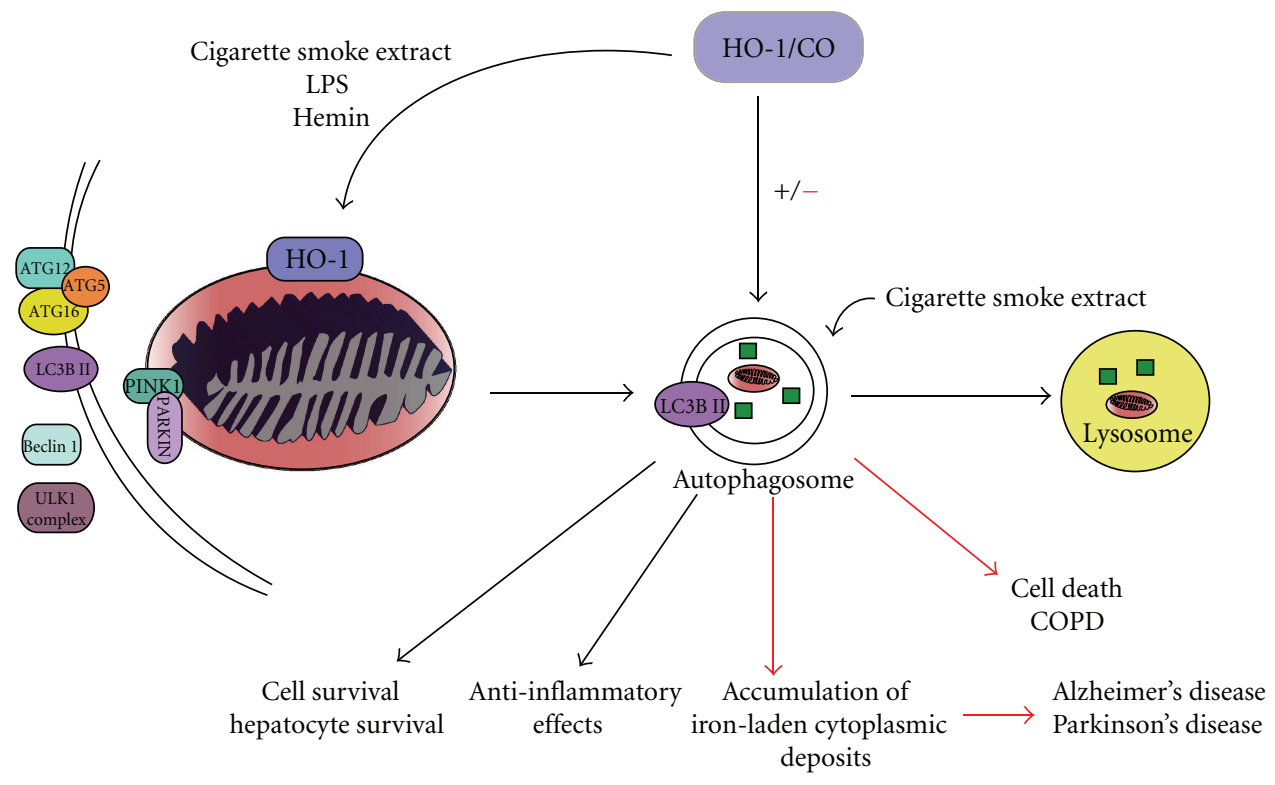

FIGURE 3: HO-1 as a regulator of autophagy. Autophagic machinery is mobilized in response to stress signals that result in mitochondrial perturbation or accumulations of protein aggregates. A number of proteins have been identified as signaling molecules in preautophagosomal assembly. These include master regulators such as the ULK1 complex, the Beclin-1/Vps34 complex, as well as the autophagic proteins LC3B (Atg8), Atgs 5, 12, 16 which transiently associate with the nascent autophagosome. In inflammation models, HO-1 has been implicated as an inducer of autophagy leading to cell survival and anti-inflammatory effects. In this regard, HO-1 may preserve mitochondrial integrity through the activation of mitochondrial-selective autophagy (mitophagy) which enhances cell survival. In models of neurodegeneration, overexpression of HO-1 leading to activation of autophagy/mitophagy may be detrimental and contribute to neuronal cell death. In lung epithelial cells, HO-1 prevents the induction of autophagy in response to cigarette smoke, leading to cell survival and inhibition of cell death pathways. Overall, the role of HO- 1 in controlling cell fate through autophagy is complex. In limited studies to date, the effect of HO- 1 on autophagy varies in a cell-type and inducer-specific fashion.

formation in renal tubular epithelial cells exposed to cisplatin promoting their survival. The absence of HO1 in renal epithelial cells treated with cisplatin results in impaired autophagy and increased apoptosis. Restoring HO1 expression in these cells reversed the impaired autophagic response and decreased susceptibility to cisplatin-induced apoptosis, validating the importance of $\mathrm{HO}-1$ expression during cisplatin injury [144]. These data suggest that the role of HO-1 in the control of autophagy is specific to differences in stimulus and cell type; however, in general, $\mathrm{HO}-1$ induction and signaling is an adaptive response to restore cellular homeostasis, much like autophagy. This dual nature of autophagy and HO-1 and the increasing number of pathologies they are associated with highlights of the importance of studying the regulation and effects of autophagy and its control by HO-1 during lung injury.

Our recent studies suggest that $\mathrm{CO}$ exposure alone has the potential to induce autophagy in epithelial cells. $\mathrm{CO}$ treatment increased the expression and activation of the autophagic protein LC3B in mouse lung, and in cultured human alveolar or bronchial epithelial cells, in a time-dependent manner [145]. Furthermore, CO exposure elicited increased autophagosome formation in epithelial cells, as determined by electron microscopy and GFPLC3 puncta assays. Recent studies indicate that ROS plays an important role in the activation of autophagy. CO upregulated mitochondria-specific generation of ROS in epithelial cells. Furthermore, CO-dependent induction of
LC3B expression was inhibited by the general antioxidant $\mathrm{N}$-acetyl-L-cysteine and the mitochondria-targeting antioxidant Mito-TEMPO, suggesting that CO promotes the autophagic process through mitochondrial ROS generation. We further examined the relationships between autophagic proteins and $\mathrm{CO}$-dependent cytoprotection, using a model of hyperoxic stress. CO protected against hyperoxia-induced cell death and inhibited hyperoxia-associated ROS production. The ability of CO to protect against hyperoxia-induced cell death and caspase- 3 activation was compromised in epithelial cells infected with LC3B-siRNA, indicating a role for autophagic proteins [145]. These studies uncover a potentially new candidate mechanism for the protective action of CO in lung cells which has not been previously explored. Further investigations are now underway to investigate elucidate the role of autophagy in lung disease and injury, and in the therapeutic potential of $\mathrm{HO}-1 / \mathrm{CO}$.

\section{Pharmacological CO}

4.1. Carbon-Monoxide-Releasing Molecules. The development of transition metal-based carbon-monoxide-releasing compounds (CORMs) has provided a pharmacological method for delivery of $\mathrm{CO}$ as a promising alternative to inhalation. The CORMs used in experimental studies to date include $\mathrm{Mn}_{2} \mathrm{CO}_{10}$ (CORM-1) and the rutheniumbased compounds tricarbonyldichlororuthenium-(II)-dimer (CORM-2) and tricarbonylchoro(glycinato)-ruthenium (II) 
(CORM-3) [146, 147]. CORM-1 and CORM-2 are soluble in organic solvents, whereas CORM-3 dissolves in water and rapidly releases $\mathrm{CO}$ in physiological fluids. A nontransition metallic water-soluble boron-containing CORM (CORMA1) has also been developed, which slowly releases CO in a $\mathrm{pH}$ and temperature-dependent fashion (half-life of $21 \mathrm{~min}$ ) [148]. This chemical difference dictates how CO causes vasorelaxation and hypotension as CORM-3 elicits a prompt and rapid vasodilatory effect, whereas CORMA1 promotes mild vasorelaxation and hypotension [149]. Recently, a novel light-sensitive CORM has been developed [150]. Interestingly, and in contrast to inhaled CO, CORMs appear to deliver $\mathrm{CO}$ directly to the tissues without significant formation of $\mathrm{CO}-\mathrm{Hb}$. There is an abundance of preclinical evidence in large and small animals showing the beneficial effects of CO, administered as a gas or as CORM, in cardiovascular disease, sepsis, and shock; cancer, acute and chronic rejection of a transplanted organ; kidney, liver injury, and some published reports in the acute lung injury field.

The chemistry of transition metals carbonyls is varied, highly versatile, and not restricted to the above-described compounds. Several subclasses of metal carbonyl compounds containing either manganese, iron, cobalt, molybdenum, or ruthenium have been synthesized and tested for their ability to act as CORMs [151]. Though the discovery of these CORM compounds opens up new possibilities, there are still several issues to overcome for medical applications, particularly those in which downstream tissue sites draining the injection site are targeted. These small molecular drugs diffuse rapidly within the body after administration and may liberate $\mathrm{CO}$ prior to reaching these target tissues. Thus, there is considerable need for developing a safe and efficient CO-delivery system. Future work in this area should be directed to the synthesis of CORMs which, beyond an effective therapeutic action and low toxicity, need molecular characteristics with appropriate absorption, distribution, metabolism, and excretion properties [25]. A recent report by Kretschmer demonstrates the synthesis of a new CORM (CORM-S1) based on iron and cysteamine, which is soluble in water and releases $\mathrm{CO}$ under irradiation with visible light, while it is widely stable in the dark [150]. This is the first example of a light-induced CO release from water-soluble iron-based CORMs, which has low toxicity, compared to that of boron-containing compounds. Hubbell and colleagues have developed micelle forms of metal carbonyl complexes that displayed slowed diffusion in tissues and better ability to target distal tissue drainage sites [152]. The CO release of the micelles was slower than that of CORM-3. COreleasing micelles efficiently attenuated the LPS-induced NF$\kappa \mathrm{B}$ activation of human monocytes while CORM-3 did not show any beneficial effects. This novel CO-delivery system based on CO-releasing micelles may be useful for therapeutic applications of CO. Efforts in medicinal chemistry development of metal carbonyl compounds are actively ongoing, which should help establish these compounds as a new class of drugs in the near future.

4.2. CORMs and Sepsis. CORM compounds are capable of delivering small amounts of $\mathrm{CO}$ to biological systems in a controlled manner and are emerging as a potential therapy for sepsis. In terms of lung physiology, most studies to date have focused on the therapeutic effects of CORMs in sepsis models. For example, CORMs reduce cytokine release in LPS-stimulated macrophages [24] and decrease inflammatory response and oxidative stress in LPS-stimulated endothelial cells [153]. In vivo, CORMs attenuate systemic inflammation and proadhesive vascular cell properties in septic and thermally injured mice by reducing nuclear factor$\kappa \mathrm{B}$ activation, protein expression of ICAM-1, and tissue granulocyte infiltration $[154,155]$. CORM-3 has been shown to prevent reoccurrence of sepsis, CORM-2 prolongs survival and reduces inflammation, while CORM-3 reduces liver injury after CLP $[155,156]$. These studies taken together have demonstrated that the CORM-dependent release of CO can reduce mortality in septic mice, suggesting that CORMs could be used therapeutically to prevent organ dysfunction and death in sepsis. As with inhaled CO, full consideration of the toxicological and physiological properties of the released $\mathrm{CO}$, including possible effects on hemodynamics, must be understood before proceeding with CORMs as clinical therapy, with additional considerations for the biological properties of the chemical backbone and transition metal components.

4.3. CORM and Ion Channels. Over the last decade, ion channels have been recognized as important effectors in the actions of $\mathrm{CO}$ and may play roles in some of the beneficial effects of CO. Members of several ion channel families are molecular targets for the action of $\mathrm{CO}$ and/or CORMs and include: (i) the large-conductance, voltage-, and $\mathrm{Ca}^{2+}$-activated $\mathrm{K}^{+}$channels [157-163]; (ii) the purinergic $\mathrm{P} 2 \mathrm{X} 2$ receptor [164]; (iii) the tandem $\mathrm{P}$ domain channel, TREK1 [165]. Interestingly, CORM-2 inhibits the purinergic P2X4 receptor [166] and K.2.1 [167]. Possible mechanisms by which $\mathrm{CO}$ regulates ion channels may include sGCdependent signaling [168], direct binding of CO to the polypeptide as proposed by Wang and $\mathrm{Wu}$ [157], indirect binding via heme [161], or modulation of cellular redox state and mitochondrial function $[167,169]$. The precise details of how CO differentially regulates each of these ion channels is beginning to be elucidated but still warrants further investigation and contradictory data has been reported for each channel [170]. For example, the most widely studied ion channel target of $\mathrm{CO}$ is the large-conductance, voltage-, and $\mathrm{Ca}^{2+}$-activated $\mathrm{K}^{+}$channel, $\mathrm{BK}_{\mathrm{Ca}}$. While a number of mechanisms have been proposed to explain how $\mathrm{CO}$ activates $\mathrm{BK}_{\mathrm{Ca}}$ channels, the exact mechanism of action is unknown. Direct binding of CO to extracellular histidines has been reported [157] but mutagenesis of these residues did not fully abolish the ability of $\mathrm{CO}$ to activate the ion channel $[160,162]$. CO has been proposed to bind to a high-affinity, channel-associated heme moiety on the $\alpha$-subunit [160], yet mutation of the key histidine residue required for heme binding does not affect CO activation of the channel [162]. Clearly, further investigation is required to determine the exact mechanisms of action.

Two studies, with opposing outcomes, have reported the regulation of voltage-activated, L-type $\mathrm{Ca}^{2+}$ channels. 
A study by Scragg et al. demonstrated that CO, applied either as the dissolved gas or from the donor molecule CORM-2, inhibits both native (rat) and recombinant (human) cardiac L-type $\mathrm{Ca}^{2+}$ channels [169]. This effect arose due to the ability of CO to bind to mitochondria, presumably by interacting at complex IV causing electron leak specifically from complex III. Such leak leads to rapid formation of ROS which causes channel inhibition through a specific interaction with three cytosine residues in the C-terminal tail of the channel's major, pore-forming subunit. Therefore, CO evokes channel modulation in the heart via production of mitochondrial ROS [169]. In another study, the opposite results were reported. Human recombinant intestinal smooth-muscle Ltype $\mathrm{Ca}^{2+}$ channels were shown to be activated by $\mathrm{CO}$ via an NO-dependent mechanism [171]. The reasons for these contrary observations remain unclear but may reflect tissuespecific splice variation of L-type $\mathrm{Ca}^{2+}$ channels, as seen for $\mathrm{O}_{2}$ regulation of L-type channels [172].

In conclusion, $\mathrm{CO}$ modulates ion channels via multiple mechanisms, and it is hoped that these pathways and targets may be exploited for therapeutic intervention in the treatment of a number of important and diverse clinical conditions.

4.4. CORM-3 and Mitochondrial Dynamics. The notion that mitochondria serve as important targets in transducing the beneficial signaling properties of $\mathrm{CO}$ has been proposed [173]. Recent studies indicate that increased mitochondrial biogenesis is part of the mechanisms by which $\mathrm{CO}$ gas and CORMs exert protective effects against cardiomyopathy and cardiac dysfunction in sepsis $[174,175]$. Studies by Lancel et al. investigated the potential of CORMs to preserve mitochondrial function in the CLP model of sepsis. CORM3 treatment in CLP-induced mice prevented the decline in mitochondrial function. Administration of CORM-3 during sepsis also stimulated mitochondrial biogenesis with corresponding increases in (PPAR- $\gamma$-) coactivator- $1 \alpha$ protein expression and mitochondrial DNA copy number. CLP was found to impair mitochondrial energetic metabolism and reduce mitochondrial biogenesis in mice [175].

Recent work by Iacono et al. shows that low-micromolar concentrations of $\mathrm{CO}$, delivered to isolated heart mitochondria by the water-soluble CORM-3, uncouple mitochondrial respiration, consequently modulating both ROS production and bioenergetic parameters. In addition, CORM-3 decreased mitochondrial membrane potential at concentrations that did not inhibit cytochrome c oxidase [176]. The CO-mediated effects were attenuated by pharmacological agents known to inhibit mitochondrial uncoupling. Taken together, this work demonstrates that CORM-3, through the liberation of $\mathrm{CO}$, represents a novel regulator of mitochondrial respiration, which in addition to fatty acids and thyroid and steroid hormones could play a crucial role in those pathological conditions for which strategies aimed at targeting mitochondrial uncoupling and metabolism are developed for therapeutic interventions.

\section{Clinical Aspects of $\mathrm{CO}$}

Studies have shown that CO exerts direct anti-inflammatory effects after LPS challenge in vitro and in an in vivo mouse model [22]. Mice exposed to 250 ppm CO for 1 hour before LPS administration responded with significantly lower levels of proinflammatory cytokines (TNF $\alpha$ and IL-1 $\beta$ ) and higher levels of IL-10 than control mice. As a consequence of this work, the role of $\mathrm{CO}$ in various rodent models has since been investigated (reviewed in [25]). On the basis of the rationale provided by these animal studies, Mayr and colleagues studied the effects of $\mathrm{CO}$ inhalation on systemic inflammation during experimental human endotoxemia. Specifically, in a randomized, double-blinded, placebo-controlled, two-way crossover trial, experimental endotoxemia was induced in healthy volunteers by injection of $2 \mathrm{ng} / \mathrm{kg}$ LPS. The potential anti-inflammatory effects of $\mathrm{CO}$ inhalation were investigated by inhalation of $500 \mathrm{ppm} \mathrm{CO}$ (leading to an increase in CO$\mathrm{Hb}$ from $1.2 \%$ to $7 \%$ ) versus synthetic air as a placebo for $1 \mathrm{~h}$. $\mathrm{CO}$ inhalation had no effect on the inflammatory response as measured by systemic cytokine production (TNF- $\alpha$, IL6 , IL- $8, \mathrm{IL}-1 \alpha$, and IL- $1 \beta$ ). In this study, no adverse side effects of CO inhalation were observed [177]. However, given the limited scope of this initial trial, and the protective characteristics of CO application in many animal models of sepsis, further more detailed clinical trials are urgently needed to reach a verdict on the efficacy of $\mathrm{CO}$ for reducing inflammation in septic patients. In contrast, a recent clinical trial demonstrates the feasibility of administering inhaled CO to humans with chronic obstructive pulmonary disease (COPD) [178]. In this study, exsmoking patients with stable COPD were subjected to CO inhalation (100-125 ppm for 2 hours/day for 4 days), which increased $\mathrm{CO}-\mathrm{Hb}$ levels to $4.5 \%$. Inhalation of CO by patients with stable COPD led to trends in reduction of sputum eosinophils and improvement of methacholine responsiveness [178]. In summary, the protective phenotype of $\mathrm{CO}$ in rodents in protecting against lung disease has not been recapitulated in human trial studies to date. One possibility is that differences in lung physiological responses to CO exist between different species. Further experiments are required to confirm the safety and efficacy of $\mathrm{CO}$ inhalation as a treatment for inflammatory lung diseases.

\section{Final Remarks}

The overexpression of HO-1 by gene transfer has now been shown to confer protection in several models of lung and vascular injury and disease, as well as systemic inflammatory diseases (i.e., sepsis). Potential clinical application of HO1 would imply targeted gene delivery or pharmacological manipulation of gene expression [179]. The development of vectors for tissue-specific delivery of HO-1 in humans may facilitate gene therapy approaches [179].

Likewise, similar protective effects have been reported for inhalation $\mathrm{CO}$ in models of acute lung injury and sepsis. The demonstrated protective properties of low-dose CO in preclinical rodent models continue to suggest promising therapeutic applications for CO (reviewed in $[21,25,180]$ ). 
More recent studies imply the stabilization of mitochondrial function and the stimulation of cellular autophagy as potential candidate mechanisms.

It should be noted that there are limitations, such that some studies have been disputed, and some negative findings reported [181, 182]. However, experimental work showing therapeutic potential of $\mathrm{CO}$ has now been extended to large animal models such as swine and nonhuman primates [89, 90].

As an alternative to inhalation of $\mathrm{CO}$, pharmacological application of CO using CORMs may provide a promising therapeutic strategy [25]. Targeted delivery of CORMs may reduce the systemic effects associated with inhaled $\mathrm{CO}$, resulting from $\mathrm{CO}-\mathrm{Hb}$ elevation, while retaining therapeutic potential. Whether direct application of CO by CORMs administration or inhalation will provide a safe and effective modality for the treatment of human disease requires further research directed at understanding the pharmacokinetics and toxicology of CO or CORMs application in humans [25].

Ultimately, the goal of this experimentation remains to translate the therapeutic potential of $\mathrm{CO}$, whether inhaled or administered through prodrugs, to possible medicinal application in human disease. Although some obstacles remain, limited human experimentation is now underway. Pilot clinical trials to date have indicated either negative efficacy for human $\mathrm{CO}$ therapy in endotoxemia or partial efficacy in COPD, while several other trials involving organ transplantation await completion [177, 178]. Currently, new clinical studies in fibrosis and sepsis are projected to begin shortly. Despite the success in animal models, which do not always directly translate to human disease, the therapeutic benefit of $\mathrm{CO}$ therapies has yet to be validated in humans.

$\begin{array}{ll}\text { Abbreviations } \\ \text { Atg: } & \text { Autophagy related gene } \\ \text { BALF: } & \text { Bronchio-alveolar lavage fluid } \\ \text { CLP: } & \text { Cecal ligation and puncture } \\ \text { CO: } & \text { Carbon monoxide } \\ \text { CO-Hb: } & \text { Carboxyhemoglobin } \\ \text { CORM: } & \text { Carbon monoxide-releasing molecule } \\ \text { COPD: } & \text { Chronic obstructive pulmonary disease } \\ \text { CSE: } & \text { Cigarette smoke extract } \\ \text { DISC: } & \text { Death inducing signaling complex } \\ \text { GFP-LC3: } & \text { Green fluorescence protein conjugated } \\ & \text { LC3B } \\ \text { HMGB-1: } & \text { High-mobility group box 1 } \\ \text { HO-1: } & \text { Heme oxygenase-1 } \\ \text { HO-2: } & \text { Heme oxygenase-2 } \\ \text { HPX: } & \text { Hemopexin } \\ \text { IL: } & \text { Interleukin } \\ \text { LC3B: } & \text { Microtubule-associated protein-1 light } \\ & \text { chain-3B } \\ \text { LPS: } & \text { Lipopolysaccharide } \\ \text { MAPK: } & \text { Mitogen activated protein kinase } \\ \text { ROS: } & \text { Reactive oxygen species } \\ \text { siRNA: } & \text { Small-interfering ribonucleic acid } \\ \text { VILI: } & \text { Ventilator-induced lung injury. }\end{array}$

\section{Acknowledgments}

This work was performed as part of a joint educational program between Boston College and Brigham and Women's Hospital, Harvard Medical School. M. Constantin is a Fellow of the Lovelace Respiratory Research Institute (LRRI), S. W. Ryter is an Adjunct Scientist of the Lovelace Respiratory Research Institute (LRRI), Albuquerque, New Mexico, and received salary support from the BWH/LRRI consortium for joint lung research.

\section{References}

[1] B. Wu, C. Hunt, and R. Morimoto, "Structure and expression of the human gene encoding major heat shock protein HSP70," Molecular and Cellular Biology, vol. 5, no. 2, pp. 330341, 1985.

[2] R. P. Beckmann, L. A. Mizzen, and W. J. Welch, "Interaction of Hsp 70 with newly synthesized proteins: implications for protein folding and assembly," Science, vol. 248, no. 4957, pp. 850-854, 1990.

[3] G. C. Li and Z. Werb, "Correlation between synthesis of heat shock proteins and development of thermotolerance in Chinese hamster fibroblasts," Proceedings of the National Academy of Sciences of the United States of America, vol. 79, no. 10, pp. 3218-3222, 1982.

[4] S. M. Keyse and R. M. Tyrrell, "Heme oxygenase is the major $32-\mathrm{kDa}$ stress protein induced in human skin fibroblasts by UVA radiation, hydrogen peroxide, and sodium arsenite," Proceedings of the National Academy of Sciences of the United States of America, vol. 86, no. 1, pp. 99-103, 1989.

[5] S. M. Keyse and R. M. Tyrrell, "Both near ultraviolet radiation and the oxidizing agent hydrogen peroxide induce a 32-kDa stress protein in normal human skin fibroblasts," The Journal of Biological Chemistry, vol. 262, no. 30, pp. 1482114825, 1987.

[6] L. A. Applegate, P. Luscher, and R. M. Tyrrell, "Induction of heme oxygenase: a general response to oxidant stress in cultured mammalian cells," Cancer Research, vol. 51, no. 3, pp. 974-978, 1991.

[7] M. Rizzardini, M. Terao, F. Falciani, and L. Cantoni, "Cytokine induction of haem oxygenase mRNA in mouse liver: interleukin 1 transcriptionally activates the haem oxygenase gene," Biochemical Journal, vol. 290, no. 2, pp. 343$347,1993$.

[8] C. M. Terry, J. A. Clikeman, J. R. Hoidal, and K. S. Callahan, "Effect of tumor necrosis factor- $\alpha$ and interleukin- $1 \alpha$ on heme oxygenase-1 expression in human endothelial cells," American Journal of Physiology, vol. 274, no. 3, pp. H883H891, 1998.

[9] S. L. Camhi, J. Alam, L. Otterbein, S. L. Sylvester, and A. M. Choi, "Induction of heme oxygenase-1 gene expression by lipopolysaccharide is mediated by AP-1 activation," American Journal of Respiratory Cell and Molecular Biology, vol. 13, no. 4, pp. 387-398, 1995.

[10] S. L. Camhi, J. Alam, G. W. Wiegand, B. Y. Chin, and A. M. K. Choi, "Transcriptional activation of the HO-1 gene by lipopolysaccharide is mediated by $5^{\prime}$ distal enhancers: role of reactive oxygen intermediates and AP-1," American Journal of Respiratory Cell and Molecular Biology, vol. 18, no. 2, pp. 226-234, 1998.

[11] R. Tenhunen, H. S. Marver, and R. Schmid, "Microsomal heme oxygenase. Characterization of the enzyme," The 
Journal of Biological Chemistry, vol. 244, no. 23, pp. 63886394, 1969.

[12] D.B. Menzel and M.O. Amdur, "Toxic response of the respiratory system," in Casarett \& Doull's Toxicology: The Basic Science of Poisons, K. Klaassen, M. O. Amdur, and J. Doull, Eds., pp. 330-358, MacMillan, New York, NY, USA, 3rd edition, 1986.

[13] L. E. Otterbein, J. K. Kolls, L. L. Mantell, J. L. Cook, J. Alam, and A. M. K. Choi, "Exogenous administration of heme oxygenase-1 by gene transfer provides protection against hyperoxia-induced lung injury," Journal of Clinical Investigation, vol. 103, no. 7, pp. 1047-1054, 1999.

[14] T. Hashiba, M. Suzuki, Y. Nagashima et al., "Adenovirusmediated transfer of heme oxygenase-1 cDNA attenuates severe lung injury induced by the influenza virus in mice," Gene Therapy, vol. 8, no. 19, pp. 1499-1507, 2001.

[15] S. Inoue, M. Suzuki, Y. Nagashima et al., "Transfer of heme oxygenase 1 cDNA by a replication-deficient adenovirus enhances interleukin 10 production from alveolar macrophages that attenuates lipopolysaccharide-induced acute lung injury in mice," Human Gene Therapy, vol. 12, no. 8, pp. 967-979, 2001.

[16] H. J. Duckers, M. Boehm, A. L. True et al., "Heme oxygenase1 protects against vascular constriction and proliferation," Nature Medicine, vol. 7, no. 6, pp. 693-698, 2001.

[17] H. Christou, T. Morita, C. M. Hsieh et al., "Prevention of hypoxia-induced pulmonary hypertension by enhancement of endogenous heme oxygenase- 1 in the rat," Circulation Research, vol. 86, no. 12, pp. 1224-1229, 2000.

[18] T. Minamino, H. Christou, C. M. Hsieh et al., "Targeted expression of heme oxygenase-1 prevents the pulmonary inflammatory and vascular responses to hypoxia," Proceedings of the National Academy of Sciences of the United States of America, vol. 98, no. 15, pp. 8798-8803, 2001.

[19] S. H. Juan, T. S. Lee, K. W. Tseng et al., "Adenovirus-mediated heme oxygenase-1 gene transfer inhibits the development of atherosclerosis in apolipoprotein e-deficient mice," Circulation, vol. 104, no. 13, pp. 1519-1525, 2001.

[20] K. Ishikawa, D. Sugawara, X. P. Wang et al., "Heme oxygenase-1 inhibits atherosclerotic lesion formation in LDL-receptor knockout mice," Circulation Research, vol. 88, no. 5, pp. 506-512, 2001.

[21] S. W. Ryter, J. Alam, and A. M. K. Choi, "Heme oxygenase$1 /$ carbon monoxide: from basic science to therapeutic applications," Physiological Reviews, vol. 86, no. 2, pp. 583-650, 2006.

[22] L. E. Otterbein, F. H. Bach, J. Alam et al., "Carbon monoxide has anti-inflammatory effects involving the mitogen- activated protein kinase pathway," Nature Medicine, vol. 6, no. 4, pp. 422-428, 2000.

[23] L. E. Otterbein, L. L. Mantell, and A. M. K. Choi, "Carbon monoxide provides protection against hyperoxic lung injury," American Journal of Physiology, vol. 276, no. 4, pp. L688-L694, 1999.

[24] P. Sawle, R. Foresti, B. E. Mann, T. R. Johnson, C. J. Green, and R. Motterlini, "Carbon monoxide-releasing molecules (CO-RMs) attenuate the inflammatory response elicited by lipopolysaccharide in RAW264.7 murine macrophages," British Journal of Pharmacology, vol. 145, no. 6, pp. 800-810, 2005.

[25] R. Motterlini and L. E. Otterbein, "The therapeutic potential of carbon monoxide," Nature Reviews Drug Discovery, vol. 9, no. 9, pp. 728-743, 2010.
[26] C. Fondevila, X. D. Shen, S. Tsuchiyashi et al., "Biliverdin therapy protects rat livers from ischemia and reperfusion injury," Hepatology, vol. 40, no. 6, pp. 1333-1341, 2004.

[27] A. Nakao, N. Murase, C. Ho, H. Toyokawa, T. R. Billiar, and S. Kanno, "Biliverdin administration prevents the formation of intimal hyperplasia induced by vascular injury," Circulation, vol. 112, no. 4, pp. 587-591, 2005.

[28] R. Öllinger, M. Bilban, A. Erat et al., "A natural inhibitor of vascular smooth muscle cell proliferation," Circulation, vol. 112, no. 7, pp. 1030-1039, 2005.

[29] S. Brouard, L. E. Otterbein, J. Anrather et al., "Carbon monoxide generated by heme oxygenase 1 suppresses endothelial cell apoptosis," Journal of Experimental Medicine, vol. 192, no. 7, pp. 1015-1025, 2000.

[30] R. Song, Z. Zhou, P. K. M. Kim et al., "Carbon monoxide promotes Fas/CD95-induced apoptosis in Jurkat cells," The Journal of Biological Chemistry, vol. 279, no. 43, pp. 4432744334, 2004.

[31] T. Morita, S. A. Mitsialis, H. Koike, Y. Liu, and S. Kourembanas, "Carbon monoxide controls the proliferation of hypoxic vascular smooth muscle cells," The Journal of Biological Chemistry, vol. 272, no. 52, pp. 32804-32809, 1997.

[32] L. E. Otterbein, B. S. Zuckerbraun, M. Haga et al., "Carbon monoxide suppresses arteriosclerotic lesions associated with chronic graft rejection and with balloon injury," Nature Medicine, vol. 9, no. 2, pp. 183-190, 2003.

[33] H. P. Kim, X. Wang, A. Nakao et al., "Caveolin-1 expression by means of $\mathrm{p} 38 \beta$ mitogen-activated protein kinase mediates the antiproliferative effect of carbon monoxide," Proceedings of the National Academy of Sciences of the United States of America, vol. 102, no. 32, pp. 11319-11324, 2005.

[34] B. S. Zuckerbraun, Y. C. Beek, B. Wegiel et al., "Carbon monoxide reverses established pulmonary hypertension," Journal of Experimental Medicine, vol. 203, no. 9, pp. 21092119, 2006.

[35] K. D. Poss and S. Tonegawa, "Heme oxygenase 1 is required for mammalian iron reutilization," Proceedings of the National Academy of Sciences of the United States of America, vol. 94, no. 20, pp. 10919-10924, 1997.

[36] M. D. Maines and A. Kappas, "Cobalt induction of hepatic heme oxygenase; with evidence that cytochrome P 450 is not essential for this enzyme activity," Proceedings of the National Academy of Sciences of the United States of America, vol. 71, no. 11, pp. 4293-4297, 1974.

[37] F. P. Guengerich, D. P. Ballou, and M. J. Coon, "Purified liver microsomal cytochrome $\mathrm{P}$ 450. Electron accepting properties and oxidation reduction potential," The Journal of Biological Chemistry, vol. 250, no. 18, pp. 7405-7414, 1975.

[38] T. Yoshida, M. Noguchi, and G. Kikuchi, "Oxygenated form of heme . heme oxygenase complex and requirement for second electron to initiate heme degradation from the oxygenated complex," The Journal of Biological Chemistry, vol. 255, no. 10, pp. 4418-4420, 1980.

[39] T. Yoshinaga, S. Sassa, and A. Kappas, "The occurrence of molecular interactions among NADPH-cytochrome c reductase, heme oxygenase, and biliverdin reductase in heme degradation," The Journal of Biological Chemistry, vol. 257, no. 13, pp. 7786-7793, 1982.

[40] M. Noguchi, T. Yoshida, and G. Kikuchi, "Specific requirement of NADPH-cytochrome $\mathrm{c}$ reductase for the microsomal heme oxygenase reaction yielding biliverdin IX $\alpha$, FEBS Letters, vol. 98, no. 2, pp. 281-284, 1979.

[41] T. Yoshida and G. Kikuchi, "Features of the reaction of heme degradation catalyzed by the reconstituted microsomal heme 
oxygenase system," The Journal of Biological Chemistry, vol. 253, no. 12, pp. 4230-4236, 1978.

[42] G. Kikuchi and T. Yoshida, "Heme catabolism by the reconstituted heme oxygenase system," Annals of Clinical Research, vol. 8, no. 17, pp. 10-17, 1976.

[43] T. Yoshida and G. Kikuchi, "Sequence of the reaction of heme catabolism catalyzed by the microsomal heme oxygenase system," FEBS Letters, vol. 48, no. 2, pp. 256-261, 1974.

[44] R. Tenhunen, M. E. Ross, H. S. Marver, and R. Schmid, "Reduced nicotinamide-adenine dinucleotide phosphate dependent biliverdin reductase: partial purification and characterization," Biochemistry, vol. 9, no. 2, pp. 298-303, 1970.

[45] R. Stocker, Y. Yamamoto, A. F. McDonagh, A. N. Glazer, and B. N. Ames, "Bilirubin is an antioxidant of possible physiological importance," Science, vol. 235, no. 4792, pp. 1043-1046, 1987.

[46] R. Stocker, A. N. Glazer, and B. N. Ames, "Antioxidant activity of albumin-bound bilirubin," Proceedings of the National Academy of Sciences of the United States of America, vol. 84, no. 16, pp. 5918-5922, 1987.

[47] C. D. King, G. R. Rios, M. D. Green, and T. R. Tephly, "UDPGlucuronosyltransferases," Current Drug Metabolism, vol. 1, no. 2, pp. 143-161, 2000.

[48] M. D. Maines, G. M. Trakshel, and R. K. Kutty, "Characterization of two constitutive forms of rat liver microsomal heme oxygenase. Only one molecular species of the enzyme is inducible," The Journal of Biological Chemistry, vol. 261, no. 1, pp. 411-419, 1986.

[49] M. D. Maines, "The heme oxygenase system: a regulator of second messenger gases," Annual Review of Pharmacology and Toxicology, vol. 37, pp. 517-554, 1997.

[50] L. A. Applegate, P. Luscher, and R. M. Tyrrell, "Induction of heme oxygenase: a general response to oxidant stress in cultured mammalian cells," Cancer Research, vol. 51, no. 3, pp. 974-978, 1991.

[51] R. Tenhunen, H. S. Marver, and R. Schmid, "The enzymatic catabolism of hemoglobin: stimulation of microsomal heme oxygenase by hemin," The Journal of Laboratory and Clinical Medicine, vol. 75, no. 3, pp. 410-421, 1970.

[52] V. S. Raju and M. D. Maines, "Coordinated expression and mechanism of induction of HSP32 (heme oxygenase1) mRNA by hyperthermia in rat organs," Biochimica et Biophysica Acta, vol. 1217, no. 3, pp. 273-280, 1994.

[53] I. Cruse and M. D. Maines, "Evidence suggesting that the two forms of heme oxygenase are products of different genes," The Journal of Biological Chemistry, vol. 263, no. 7, pp. 33483353, 1988.

[54] G. M. Trakshel, R. K. Kutty, and M. D. Maines, "Purification and characterization of the major constitutive form of testicular heme oxygenase. The noninducible isoform," The Journal of Biological Chemistry, vol. 261, no. 24, pp. 1113111137, 1986.

[55] W. K. McCoubrey, T. J. Huang, and M. D. Maines, "Heme oxygenase- 2 is a hemoprotein and binds heme through heme regulatory motifs that are not involved in heme catalysis," The Journal of Biological Chemistry, vol. 272, no. 19, pp. 12568 12574, 1997.

[56] M. D. Maines, B. C. Eke, and X. Zhao, "Corticosterone promotes increased heme oxygenase-2 protein and transcript expression in the newborn rat brain," Brain Research, vol. 722, no. 1-2, pp. 83-94, 1996.

[57] V. S. Raju, W. K. McCoubrey, and M. D. Maines, "Regulation of heme oxygenase- 2 by glucocorticoids in neonatal rat brain: characterization of a functional glucocorticoid response element," Biochimica et Biophysica Acta, vol. 1351, no. 1-2, pp. 89-104, 1997.

[58] P. J. Lee, J. Alam, G. W. Wiegand, and A. M. K. Choi, "Overexpression of heme oxygenase-1 in human pulmonary epithelial cells results in cell growth arrest and increased resistance to hyperoxia," Proceedings of the National Academy of Sciences of the United States of America, vol. 93, no. 19, pp. 10393-10398, 1996.

[59] I. Petrache, L. E. Otterbein, J. Alam, G. W. Wiegand, and A. M. K. Choi, "Heme oxygenase-1 inhibits TNF- $\alpha$ induced apoptosis in cultured fibroblasts," American Journal of Physiology, vol. 278, no. 2, pp. L312-L319, 2000.

[60] G. Carlin, R. Djursäter, and K. E. Arfors, "Inhibition of hemepromoted enzymatic lipid peroxidation by desferrioxamine and EDTA," Upsala Journal of Medical Sciences, vol. 93, no. 3, pp. 215-223, 1988.

[61] A. L. Tappel, "The mechanism of the oxidation of unsaturated fatty acids catalyzed by hematin compounds," Archives of Biochemistry and Biophysics, vol. 44, no. 2, pp. 378-395, 1953.

[62] J. Balla, H. S. Jacob, G. Balla, K. Nath, J. W. Eaton, and G. M. Vercellotti, "Endothelial-cell heme uptake from heme proteins: induction of sensitization and desensitization to oxidant damage," Proceedings of the National Academy of Sciences of the United States of America, vol. 90, no. 20, pp. 9285-9289, 1993.

[63] D. M. Suttner and P. A. Dennery, "Reversal of HO-1 related cytoprotection with increased expression is due to reactive iron,” FASEB Journal, vol. 13, no. 13, pp. 1800-1809, 1999.

[64] G. F. Vile and R. M. Tyrrell, "Oxidative stress resulting from ultraviolet A irradiation of human skin fibroblasts leads to a heme oxygenase-dependent increase in ferritin," The Journal of Biological Chemistry, vol. 268, no. 20, pp. 14678-14681, 1993.

[65] J. Z. He, J. J. D. Ho, S. Gingerich, D. W. Courtman, P. A. Marsden, and M. E. Ward, "Enhanced translation of heme oxygenase-2 preserves human endothelial cell viability during hypoxia," The Journal of Biological Chemistry, vol. 285, no. 13, pp. 9452-9461, 2010.

[66] A. Yachie, Y. Niida, T. Wada et al., "Oxidative stress causes enhanced endothelial cell injury in human heme oxygenase1 deficiency," Journal of Clinical Investigation, vol. 103, no. 1, pp. 129-135, 1999.

[67] K. D. Poss and S. Tonegawa, "Reduced stress defense in heme oxygenase 1-deficient cells," Proceedings of the National Academy of Sciences of the United States of America, vol. 94, no. 20, pp. 10925-10930, 1997.

[68] S. Doré, M. Takahashi, C. D. Ferris, L. D. Hester, D. Guastella, and S. H. Snyder, "Bilirubin, formed by activation of heme oxygenase-2, protects neurons against oxidative stress injury," Proceedings of the National Academy of Sciences of the United States of America, vol. 96, no. 5, pp. 2445-2450, 1999.

[69] T. W. Wu, J. Wu, R. K. Li, D. Mickle, and D. Carey, "Albuminbound bilirubins protect human ventricular myocytes against oxyradical damage," Biochemistry and Cell Biology, vol. 69 , no. $10-11$, pp. 683-688, 1991.

[70] R. Öllinger, H. Wang, K. Yamashita et al., "Therapeutic applications of bilirubin and biliverdin in transplantation," Antioxidants and Redox Signaling, vol. 9, no. 12, pp. 21752185, 2007.

[71] R. Foresti, C. J. Green, and R. Motterlini, “Generation of bile pigments by haem oxygenase: a refined cellular strategy in 
response to stressful insults," Biochemical Society Symposium, vol. 71, pp. 177-192, 2004.

[72] P. A. Dennery, A. F. McDonagh, D. R. Spitz, and P. A. Rodgers, "Hyperbilirubinemia results in reduced oxidative injury in neonatal Gunn rats exposed to hyperoxia," Free Radical Biology and Medicine, vol. 19, no. 4, pp. 395-404, 1995.

[73] H. A. Schwertner, W. G. Jackson, and G. Tolan, "Association of low serum concentration of bilirubin with increased risk of coronary artery disease," Clinical Chemistry, vol. 40, no. 1, pp. 18-23, 1994.

[74] L. H. Breimer, K. A. Spyropolous, A. F. Winder, D. P. Mikhailidis, and G. Hamilton, "Is bilirubin protective against coronary artery disease?" Clinical Chemistry, vol. 40, no. 10, pp. 1987-1988, 1994.

[75] L. H. Breimer, G. Wannamethee, S. Ebrahim, and A. G. Shaper, "Serum bilirubin and risk of ischemic heart disease in middle-aged British men," Clinical Chemistry, vol. 41, no. 10, pp. 1504-1508, 1995.

[76] D. Erdogan, H. Gullu, E. Yildirim et al., "Low serum bilirubin levels are independently and inversely related to impaired flow-mediated vasodilation and increased carotid intimamedia thickness in both men and women," Atherosclerosis, vol. 184, no. 2, pp. 431-437, 2006.

[77] L. Vítek, M. Jirsa Jr., M. Brodanová et al., "Gilbert syndrome and ischemic heart disease: a protective effect of elevated bilirubin levels," Atherosclerosis, vol. 160, no. 2, pp. 449-456, 2002.

[78] A. C. Bulmer, J. T. Blanchfield, I. Toth, R. G. Fassett, and J. S. Coombes, "Improved resistance to serum oxidation in Gilbert's syndrome: a mechanism for cardiovascular protection," Atherosclerosis, vol. 199, no. 2, pp. 390-396, 2008.

[79] J. F. Watchko, "Hyperbilirubinemia and bilirubin toxicity in the late preterm infant," Clinics in Perinatology, vol. 33, no. 4, pp. 839-852, 2006.

[80] J. K. Sarady-Andrews, F. Liu, D. Gallo et al., "Biliverdin administration protects against endotoxin-induced acute lung injury in rats," American Journal of Physiology, vol. 289, no. 6, pp. L1131-L1137, 2005.

[81] S. G. Tullius, M. Nieminen-Kelha, and U. Bachmann, "Induction of heme-oxygenase-1 prevents ischemia/reperfusion injury and improves long-term graft outcome in rat renal allografts," Transplantation Proceedings, vol. 33, no. 1-2, pp. 1286-1287, 2001.

[82] Y. Avihingsanon, N. Ma, E. Csizmadia et al., "Expression of protective genes in human renal allografts: a regulatory response to injury associated with graft rejection," Transplantation, vol. 73, no. 7, pp. 1079-1085, 2002.

[83] F. Amersi, R. Buelow, H. Kato et al., "Upregulation of heme oxygenase-1 protects genetically fat Zucker rat livers from ischemia/reperfusion injury," Journal of Clinical Investigation, vol. 104, no. 11, pp. 1631-1639, 1999.

[84] S. W. Chung, X. Liu, A. A. Macias, R. M. Baron, and M. A. Perrella, "Heme oxygenase-1-derived carbon monoxide enhances the host defense response to microbial sepsis in mice," Journal of Clinical Investigation, vol. 118, no. 1, pp. 239-247, 2008.

[85] R. Larsen, R. Gozzelino, V. Jeney et al., "A central role for free heme in the pathogenesis of severe sepsis," Science Translational Medicine, vol. 2, no. 51, Article ID 51ra71, 2010.

[86] R. Takamiya, C. C. Hung, S. R. Hall et al., "High-mobility group box 1 contributes to lethality of endotoxemia in heme oxygenase-1-deficient mice," American Journal of Respiratory Cell and Molecular Biology, vol. 41, no. 2, pp. 129-135, 2009.

[87] K. Tsoyi, Y. L. Tae, S. L. Young et al., "Heme-oxygenase-1 induction and carbon monoxide-releasing molecule inhibit lipopolysaccharide (LPS)-induced high-mobility group box 1 release in vitro and improve survival of mice in LPS- and cecal ligation and puncture-induced sepsis model in vivo," Molecular Pharmacology, vol. 76, no. 1, pp. 173-182, 2009.

[88] J. K. Sarady, B. S. Zuckerbraun, M. Bilban et al., "Carbon monoxide protection against endotoxic shock involves reciprocal effects on iNOS in the lung and liver," The FASEB Journal, vol. 18, no. 7, pp. 854-856, 2004.

[89] S. Mazzola, M. Forni, M. Albertini et al., "Carbon monoxide pretreatment prevents respiratory derangement and ameliorates hyperacute endotoxic shock in pigs," FASEB Journal, vol. 19, no. 14, pp. 2045-2047, 2005.

[90] L. A. Mitchell, M. M. Channell, C. M. Royer, S. W. Ryter, A. M. K. Choi, and J. D. McDonald, "Evaluation of inhaled carbon monoxide as an anti-inflammatory therapy in a nonhuman primate model of lung inflammation," American Journal of Physiology, vol. 299, no. 6, pp. L891-L897, 2010.

[91] K. J. Davies, "Oxidative stress: the paradox of aerobic life," Biochemical Society symposium, vol. 61, pp. 1-31, 1995.

[92] R. M. Jackson, "Molecular, pharmacologic, and clinical aspects of oxygen-induced lung injury," Clinics in Chest Medicine, vol. 11, no. 1, pp. 73-86, 1990.

[93] P. J. Lee, J. Alam, S. L. Sylvester, N. Inamdar, L. Otterbein, and A. M. K. Choi, "Regulation of heme oxygenase-1 expression in vivo and in vitro in hyperoxic lung injury," American Journal of Respiratory Cell and Molecular Biology, vol. 14, no. 6, pp. 556-568, 1996.

[94] L. E. Otterbein, S. L. Otterbein, E. Ifedigbo et al., "MKK3 mitogen activated protein kinase pathway mediates carbon monoxide-induced protection against oxidant induced lung injury," American Journal of Pathology, vol. 163, no. 6, pp. 2555-2563, 2003.

[95] X. Zhang, P. Shan, G. Jiang et al., "Endothelial STAT3 is essential for the protective effects of HO-1 in oxidantinduced lung injury," The FASEB Journal, vol. 20, no. 12, pp. 2156-2158, 2006.

[96] X. Wang, Y. Wang, H. P. Kim, K. Nakahira, S. W. Ryter, and A. M. K. Choi, "Carbon monoxide protects against hyperoxia-induced endothelial cell apoptosis by inhibiting reactive oxygen species formation," The Journal of Biological Chemistry, vol. 282, no. 3, pp. 1718-1726, 2007.

[97] R. G. Brower, M. A. Matthay, A. Morris, D. Schoenfeld, B. T. Thompson, and A. Wheeler, "Ventilation with lower tidal volumes as compared with traditional tidal volumes for acute lung injury and the acute respiratory distress syndrome," The New England Journal of Medicine, vol. 342, no. 18, pp. 13011308, 2000.

[98] K. Tsushima, L. S. King, N. R. Aggarwal, A. De Gorordo, F. R. D’Alessio, and K. Kubo, "Acute lung injury review," Internal Medicine, vol. 48, no. 9, pp. 621-630, 2009.

[99] A. S. Slutsky, "Lung injury caused by mechanical ventilation," Chest, vol. 116, pp. 9S-15S, 1999.

[100] T. Dolinay, M. Szilasi, M. Liu, and A. M. K. Choi, "Inhaled carbon monoxide confers antiinflammatory effects against ventilator-induced lung injury," American Journal of Respiratory and Critical Care Medicine, vol. 170, no. 6, pp. 613-620, 2004.

[101] A. Hoetzel, R. Schmidt, S. Vallbracht et al., "Carbon monoxide prevents ventilator-induced lung injury via caveolin-1," Critical Care Medicine, vol. 37, no. 5, pp. 1708-1715, 2009. 
[102] A. Hoetzel, T. Dolinay, S. Vallbracht et al., "Carbon monoxide protects against ventilator-induced lung injury via PPAR- $\gamma$ and inhibition of Egr-1," American Journal of Respiratory and Critical Care Medicine, vol. 177, no. 11, pp. 1223-1232, 2008.

[103] M. Bilban, F. H. Bach, S. L. Otterbein et al., "Carbon monoxide orchestrates a protective response through PPAR $y$," Immunity, vol. 24, no. 5, pp. 601-610, 2006.

[104] M. Althaus, M. Fronius, Y. Buchäckert et al., "Carbon monoxide rapidly impairs alveolar fluid clearance by inhibiting epithelial sodium channels," American Journal of Respiratory Cell and Molecular Biology, vol. 41, no. 6, pp. 639-650, 2009.

[105] X. Zhang, P. Shan, J. Alam, R. J. Davis, R. A. Flavell, and P. J. Lee, "Carbon monoxide modulates Fas/Fas ligand, caspases, and $\mathrm{Bcl}-2$ family proteins via the $\mathrm{p} 38 \alpha$ mitogen-activated protein kinase pathway during ischemia-reperfusion lung injury," The Journal of Biological Chemistry, vol. 278, no. 24, pp. 22061-22070, 2003.

[106] X. Zhang, P. Shan, L. E. Otterbein et al., "Carbon monoxide inhibition of apoptosis during ischemia-reperfusion lung injury is dependent on the p38 mitogen-activated protein kinase pathway and involves caspase 3," The Journal of Biological Chemistry, vol. 278, no. 2, pp. 1248-1258, 2003.

[107] X. Zhang, P. Shan, J. Alam, X. Y. Fu, and P. J. Lee, "Carbon monoxide differentially modulates STAT1 and STAT3 and inhibits apoptosis via a phosphatidylinositol 3-kinase/Akt and p38 kinase-dependent STAT3 pathway during anoxiareoxygenation injury," The Journal of Biological Chemistry, vol. 280, no. 10, pp. 8714-8721, 2005.

[108] T. Fujita, K. Toda, A. Karimova et al., "Paradoxical rescue from ischemic lung injury by inhaled carbon monoxide driven by derepression of fibrinolysis," Nature Medicine, vol. 7, no. 5, pp. 598-604, 2001.

[109] S. Mishra, T. Fujita, V. M. Lama et al., "Carbon monoxide rescues ischemic lungs by interrupting MAPK-driven expression of early growth response 1 gene and its downstream target genes," Proceedings of the National Academy of Sciences of the United States of America, vol. 103, no. 13, pp. 51915196, 2006.

[110] R. Song, M. Kubo, D. Morse et al., "Carbon monoxide induces cytoprotection in rat orthotopic lung transplantation via anti-inflammatory and anti-apoptotic effects," American Journal of Pathology, vol. 163, no. 1, pp. 231-242, 2003.

[111] J. Kohmoto, A. Nakao, T. Kaizu et al., "Low-dose carbon monoxide inhalation prevents ischemia/reperfusion injury of transplanted rat lung grafts," Surgery, vol. 140, no. 2, pp. 179$185,2006$.

[112] J. Kohmoto, A. Nakao, R. Sugimoto et al., "Carbon monoxide-saturated preservation solution protects lung grafts from ischemia-reperfusion injury," Journal of Thoracic and Cardiovascular Surgery, vol. 136, no. 4, pp. 1067-1075, 2008.

[113] N. Hangai-Hoger, A. G. Tsai, P. Cabrales, M. Suematsu, and M. Intaglietta, "Microvascular and systemic effects following top load administration of saturated carbon monoxide-saline solution," Critical Care Medicine, vol. 35, no. 4, pp. 11231132, 2007.

[114] S. F. Yet, M. A. Perrella, M. D. Layne et al., "Hypoxia induces severe right ventricular dilatation and infarction in heine oxygenase-1 null mice," Journal of Clinical Investigation, vol. 103, no. 8, pp. R23-R29, 1999.

[115] H. Zhou, H. Liu, S. L. Porvasnik et al., "Heme oxygenase1 mediates the protective effects of rapamycin in monocrotaline-induced pulmonary hypertension," Laboratory Investigation, vol. 86, no. 1, pp. 62-71, 2006.
[116] E. Dubuis, M. Potier, R. Wang, and C. Vandier, "Continuous inhalation of carbon monoxide attenuates hypoxic pulmonary hypertension development presumably through activation of BKCa channels," Cardiovascular Research, vol. 65, no. 3, pp. 751-761, 2005.

[117] A. Kelekar, "Autophagy," Annals of the New York Academy of Sciences, vol. 1066, pp. 259-271, 2005.

[118] C. He and D. J. Klionsky, "Regulation mechanisms and signaling pathways of autophagy," Annual Review of Genetics, vol. 43, pp. 67-93, 2009.

[119] B. Levine and D. J. Klionsky, "Development by selfdigestion: molecular mechanisms and biological functions of autophagy," Developmental Cell, vol. 6, no. 4, pp. 463-477, 2004.

[120] N. Mizushima, B. Levine, A. M. Cuervo, and D. J. Klionsky, "Autophagy fights disease through cellular self-digestion," Nature, vol. 451, no. 7182, pp. 1069-1075, 2008.

[121] D. J. Klionsky and S. D. Emr, "Autophagy as a regulated pathway of cellular degradation," Science, vol. 290, no. 5497, pp. 1717-1721, 2000.

[122] T. Yorimitsu and D. J. Klionsky, "Autophagy: molecular machinery for self-eating," Cell Death and Differentiation, vol. 12, no. 2, pp. 1542-1552, 2005.

[123] B. Levine, N. Mizushima, and H. W. Virgin, "Autophagy in immunity and inflammation," Nature, vol. 469, no. 7330, pp. 323-335, 2011.

[124] B. Ravikumar, S. Sarkar, J. E. Davies et al., "Regulation of mammalian autophagy in physiology and pathophysiology," Physiological Reviews, vol. 90, no. 4, pp. 1383-1435, 2010.

[125] Z. Yang and D. J. Klionsky, "Mammalian autophagy: core molecular machinery and signaling regulation," Current Opinion in Cell Biology, vol. 22, no. 2, pp. 124-131, 2010.

[126] X. H. Liang, S. Jackson, M. Seaman et al., "Induction of autophagy and inhibition of tumorigenesis by beclin 1," Nature, vol. 402, no. 6762, pp. 672-676, 1999.

[127] I. Tanida, T. Ueno, and E. Kominami, "LC3 conjugation system in mammalian autophagy," International Journal of Biochemistry and Cell Biology, vol. 36, no. 12, pp. 2503-2518, 2004.

[128] D. R. Green, L. Galluzzi, and G. Kroemer, "Mitochondria and the autophagy-inflammation-cell death axis in organismal aging," Science, vol. 333, no. 6046, pp. 1109-1112, 2011.

[129] B. Levine and J. Yuan, "Autophagy in cell death: an innocent convict?" Journal of Clinical Investigation, vol. 115, no. 10, pp. 2679-2688, 2005.

[130] Y. Tsujimoto and S. Shimizu, "Another way to die: autophagic programmed cell death," Cell Death and Differentiation, vol. 12, no. 2, supplement, pp. 1528-1534, 2005.

[131] J. Debnath, K. R. Mills, N. L. Collins, M. J. Reginato, S. K. Muthuswamy, and J. S. Brugge, "The role of apoptosis in creating and maintaining luminal space within normal and oncogene-expressing mammary acini," Cell, vol. 111, no. 1, pp. 29-40, 2002.

[132] L. Jia, R. R. Dourmashkin, P. D. Allen, A. B. Gray, A. C. Newland, and S. M. Kelsey, "Inhibition of autophagy abrogates tumour necrosis factor $\alpha$ induced apoptosis in human T-lymphoblastic leukaemic cells," British Journal of Haematology, vol. 98, no. 3, pp. 673-685, 1997.

[133] B. Inbal, S. Bialik, I. Sabanay, G. Shani, and A. Kimchi, "DAP kinase and DRP-1 mediate membrane blebbing and the formation of autophagic vesicles during programmed cell death," Journal of Cell Biology, vol. 157, no. 3, pp. 455-468, 2002. 
[134] F. Zhou, Y. Yang, and D. Xing, "Bcl-2 and Bcl-xL play important roles in the crosstalk between autophagy and apoptosis," FEBS Journal, vol. 278, no. 3, pp. 403-413, 2011.

[135] V. M. Aita, X. H. Liang, V. V. V. S. Murty et al., "Cloning and genomic organization of beclin 1, a candidate tumor suppressor gene on chromosome 17q21," Genomics, vol. 59, no. 1, pp. 59-65, 1999.

[136] S. Pattingre, A. Tassa, X. Qu et al., "Bcl-2 antiapoptotic proteins inhibit Beclin 1-dependent autophagy," Cell, vol. 122, no. 6, pp. 927-939, 2005.

[137] S. Shimizu, T. Kanaseki, N. Mizushima et al., "Role of Bcl-2 family proteins in a non-apoptopic programmed cell death dependent on autophagy genes," Nature Cell Biology, vol. 6, no. 12, pp. 1221-1228, 2004.

[138] Z. H. Chen, H. C. Lam, Y. Jin et al., "Autophagy protein microtubule-associated protein 1 light chain-3B (LC3B) activates extrinsic apoptosis during cigarette smoke-induced emphysema," Proceedings of the National Academy of Sciences of the United States of America, vol. 107, no. 44, pp. 18880$18885,2010$.

[139] H. P. Kim, X. Wang, Z. H. Chen et al., "Autophagic proteins regulate cigarette smoke-induced apoptosis:Protective role of heme oxygenase-1," Autophagy, vol. 4, no. 7, pp. 887-895, 2008.

[140] D. J. Slebos, S. W. Ryter, M. van der Toorn et al., "Mitochondrial localization and function of heme oxygenase-1 in cigarette smoke-induced cell death," American Journal of Respiratory Cell and Molecular Biology, vol. 36, no. 4, pp. 409417, 2007.

[141] E. H. Carchman, J. Rao, P. A. Loughran, M. R. Rosengart, and B. S. Zuckerbraun, "Heme oxygenase-1-mediated autophagy protects against hepatocyte cell death and hepatic injury from infection/sepsis in mice," Hepatology, vol. 53, no. 6, pp. 20532062, 2011.

[142] P. Waltz, E. H. Carchman, A. C. Young et al., "Lipopolysaccaride induces autophagic signaling in macrophages via a TLR4, heme oxygenase-1 dependent pathway," Autophagy, vol. 7, no. 3, pp. 315-320, 2011.

[143] H. Zukor, W. Song, A. Liberman et al., "HO-1-mediated macroautophagy: a mechanism for unregulated iron deposition in aging and degenerating neural tissues," Journal of Neurochemistry, vol. 109, no. 3, pp. 776-791, 2009.

[144] S. Bolisetty, A. M. Traylor, J. Kim et al., "Heme oxygenase1 inhibits renal tubular macroautophagy in acute kidney injury," Journal of the American Society of Nephrology, vol. 21, no. 10, pp. 1702-1712, 2010.

[145] S. J. Lee, S. W. Ryter, J. F. Xu et al., "Carbon monoxide activates autophagy via mitochondrial reactive oxygen species formation," American Journal of Respiratory Cell and Molecular Biology, vol. 45, no. 4, pp. 867-873, 2011.

[146] R. Motterlini, B. E. Mann, and R. Foresti, "Therapeutic applications of carbon monoxide-releasing molecules," Expert Opinion on Investigational Drugs, vol. 14, no. 11, pp. 13051318, 2005.

[147] R. Foresti, M. G. Bani-Hani, and R. Motterlini, "Use of carbon monoxide as a therapeutic agent: promises and challenges," Intensive Care Medicine, vol. 34, no. 4, pp. 649-658, 2008.

[148] R. Motterlini, P. Sawle, J. Hammad et al., "CORM-A1: a new pharmacologically active carbon monoxide-releasing molecule," FASEB Journal, vol. 19, no. 2, pp. 284-286, 2005.

[149] R. Foresti, J. Hammad, J. E. Clark et al., "Vasoactive properties of CORM-3, a novel water-soluble carbon monoxide-releasing molecule," British Journal of Pharmacology, vol. 142, no. 3, pp. 453-460, 2004.

[150] R. Kretschmer, G. Gessner, H. Görls, S. H. Heinemann, and M. Westerhausen, "Dicarbonyl-bis(cysteamine)iron(II): a light induced carbon monoxide releasing molecule based on iron (CORM-S1)," Journal of Inorganic Biochemistry, vol. 105, no. 1, pp. 6-9, 2011.

[151] G. L. Bannenberg and H. L. A. Vieira, "Therapeutic applications of the gaseous mediators carbon monoxide and hydrogen sulfide," Expert Opinion on Therapeutic Patents, vol. 19, no. 5, pp. 663-682, 2009.

[152] B. Sun, X. Zou, Y. Chen, P. Zhang, and G. Shi, "Preconditioning of carbon monoxide releasing molecule-derived CO attenuates LPS-induced activation of HUVEC," International Journal of Biological Sciences, vol. 4, no. 5, pp. 270-278, 2008.

[153] U. Hasegawa, A. J. van der Vlies, E. Simeoni, C. Wandrey, and J. A. Hubbell, "Carbon monoxide-releasing micelles for immunotherapy," Journal of the American Chemical Society, vol. 132, no. 51, pp. 18273-18280, 2010.

[154] B. Sun, H. Sun, C. Liu, J. Shen, Z. Chen, and X. Chen, "Role of CO-releasing molecules liberated CO in attenuating leukocytes sequestration and inflammatory responses in the lung of thermally injured mice," Journal of Surgical Research, vol. 139, no. 1, pp. 128-135, 2007.

[155] G. Cepinskas, K. Katada, A. Bihari, and R. F. Potter, "Carbon monoxide liberated from carbon monoxide-releasing molecule CORM-2 attenuates inflammation in the liver of septic mice," American Journal of Physiology, vol. 294, no. 1, pp. G184-G191, 2007.

[156] S. Mizuguchi, J. Stephen, R. Bihari et al., "CORM-3-derived CO modulates polymorphonuclear leukocyte migration across the vascular endothelium by reducing levels of cell surface-bound elastase," American Journal of Physiology, vol. 297, no. 3, pp. H920-H929, 2009.

[157] R. Wang and $\mathrm{L}$. Wu, "The chemical modification of $\mathrm{K}(\mathrm{Ca})$ channels by carbon monoxide in vascular smooth muscle cells," The Journal of Biological Chemistry, vol. 272, no. 13, pp. 8222-8226, 1997.

[158] A. M. Riesco-Fagundo, M. T. Pérez-García, C. González, and J. R. López-López, " $\mathrm{O}_{2}$ modulates large-conductance $\mathrm{Ca}^{2+}$-dependent $\mathrm{K}^{+}$channels of rat chemoreceptor cells by a membrane-restricted and CO-sensitive mechanism," Circulation Research, vol. 89, no. 5, pp. 430-436, 2001.

[159] S. E. J. Williams, P. Wootton, H. S. Mason et al., "Hemoxygenase-2 is an oxygen sensor for a calcium-sensitive potassium channel," Science, vol. 306, no. 5704, pp. 20932097, 2004.

[160] S. E. Williams, S. P. Brazier, N. Baban et al., "A structural motif in the C-terminal tail of slol confers carbon monoxide sensitivity to human BKCa channels," Pflugers Archiv, vol. 456, no. 3, pp. 561-572, 2008.

[161] J. H. Jaggar, A. Li, H. Parfenova et al., "Heme is a carbon monoxide receptor for large-conductance $\mathrm{Ca} 2+$-activated K+ channels," Circulation Research, vol. 97, no. 8, pp. 805812, 2005.

[162] S. Hou, R. Xu, S. H. Heinemann, and T. Hoshi, "The RCK1 high-affinity $\mathrm{Ca}^{2+}$ sensor confers carbon monoxide sensitivity to Slo1 BK channels," Proceedings of the National Academy of Sciences of the United States of America, vol. 105, no. 10, pp. 4039-4043, 2008.

[163] V. Telezhkin, S. P. Brazier, R. Mears, C. T. Müller, D. Riccardi, and P. J. Kemp, "Cysteine residue 911 in C-terminal tail of human $\mathrm{BKCa} \alpha$ channel subunit is crucial for its activation 
by carbon monoxide," Pflugers Archiv European Journal of Physiology, vol. 461, no. 6, pp. 665-675, 2011.

[164] W. Wilkinson, H. C. Gadeberg, A. W. J. Harrison, N. D. Allen, D. Riccardi, and P. J. Kemp, "Carbon monoxide is a rapid modulator of recombinant and native P2X 2 ligand-gated ion channels," British Journal of Pharmacology, vol. 158, no. 3, pp. 862-871, 2009.

[165] M. L. Dallas, J. L. Scragg, and C. Peers, "Modulation of hTREK-1 by carbon monoxide," NeuroReport, vol. 19, no. 3, pp. 345-348, 2008.

[166] W. J. Wilkinson and P. J. Kemp, "The carbon monoxide donor, CORM-2, is an antagonist of ATP-gated, human P2X4 receptors," Purinergic Signalling, vol. 7, no. 1, pp. 57-64, 2011.

[167] M. L. Dallas, J. P. Boyle, C. J. Milligan et al., "Carbon monoxide protects against oxidant-induced apoptosis via inhibition of Kv2.1," FASEB Journal, vol. 25, no. 5, pp. 15191530, 2011.

[168] A. Rich, G. Farrugia, and J. L. Rae, "Carbon monoxide stimulates a potassium-selective current in rabbit corneal epithelial cells," American Journal of Physiology, vol. 267, no. 2, pp. C435-C442, 1994.

[169] J. L. Scragg, M. L. Dallas, J. A. Wilkinson, G. Varadi, and C. Peers, "Carbon monoxide inhibits L-type $\mathrm{Ca}^{2+}$ channels via redox modulation of key cysteine residues by mitochondrial reactive oxygen species," The Journal of Biological Chemistry, vol. 283, no. 36, pp. 24412-24419, 2008.

[170] W. J. Wilkinson and P. J. Kemp, "Carbon monoxide: an emerging regulator of ion channels," Journal of Physiology, vol. 589, no. 13, pp. 3055-3062, 2011.

[171] I. Lim, S. J. Gibbons, G. L. Lyford et al., "Carbon monoxide activates human intestinal smooth muscle L-type $\mathrm{Ca}^{2+}$ channels through a nitric oxide-dependent mechanism," American Journal of Physiology, vol. 288, no. 1, pp. G7-G14, 2005.

[172] I. M. Fearon, G. Varadi, S. Koch, I. Isaacsohn, S. G. Ball, and C. Peers, "Splice variants reveal the region involved in oxygen sensing by recombinant human L-type $\mathrm{Ca}^{2+}$ channels," Circulation Research, vol. 87, no. 7, pp. 537-539, 2000.

[173] M. Desmard, J. Boczkowski, J. Poderoso, and R. Motterlini, "Mitochondrial and cellular heme-dependent proteins as targets for the bioactive function of the heme oxygenase/carbon monoxide system," Antioxidants and Redox Signaling, vol. 9, no. 12, pp. 2139-2155, 2007.

[174] H. B. Suliman, M. S. Carraway, A. S. Ali, C. M. Reynolds, K. E. Welty-Wolf, and C. A. Piantadosi, "The CO/HO system reverses inhibition of mitochondrial biogenesis and prevents murine doxorubicin cardiomyopathy," Journal of Clinical Investigation, vol. 117, no. 12, pp. 3730-3741, 2007.

[175] S. Lancel, S. M. Hassoun, R. Favory, B. Decoster, R. Motterlini, and R. Neviere, "Carbon monoxide rescues mice from lethal sepsis by supporting mitochondrial energetic metabolism and activating mitochondrial biogenesis," Journal of Pharmacology and Experimental Therapeutics, vol. 329, no. 2, pp. 641-648, 2009.

[176] L. Lo Iacono, J. Boczkowski, R. Zini et al., "A carbon monoxide-releasing molecule (CORM-3) uncouples mitochondrial respiration and modulates the production of reactive oxygen species," Free Radical Biology and Medicine, vol. 50, no. 11, pp. 1556-1564, 2011.

[177] F. B. Mayr, A. Spiel, J. Leitner et al., "Effects of carbon monoxide inhalation during experimental endotoxemia in humans," American Journal of Respiratory and Critical Care Medicine, vol. 171, no. 4, pp. 354-360, 2005.

[178] E. Bathoorn, D. J. Slebos, D. S. Postma et al., "Antiinflammatory effects of inhaled carbon monoxide in patients with COPD: a pilot study," European Respiratory Journal, vol. 30, no. 6, pp. 1131-1137, 2007.

[179] N. G. Abraham, A. Asija, G. Drummond, and S. Peterson, "Heme oxygenase -1 gene therapy: recent advances and therapeutic applications," Current Gene Therapy, vol. 7, no. 2, pp. 89-108, 2007.

[180] S. W. Ryter and A. M. K. Choi, "Heme oxygenase-1/carbon monoxide: from metabolism to molecular therapy," American Journal of Respiratory Cell and Molecular Biology, vol. 41, no. 3, pp. 251-260, 2009.

[181] S. Ghosh, M. R. Wilson, S. Choudhury et al., "Effects of inhaled carbon monoxide on acute lung injury in mice," American Journal of Physiology, vol. 288, no. 6, pp. L1003L1009, 2005.

[182] C. E. Clayton, M. S. Carraway, H. B. Suliman et al., "Inhaled carbon monoxide and hyperoxic lung injury in rats," American Journal of Physiology, vol. 281, no. 4, pp. L949-L957, 2001. 


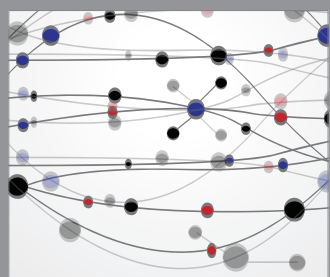

The Scientific World Journal
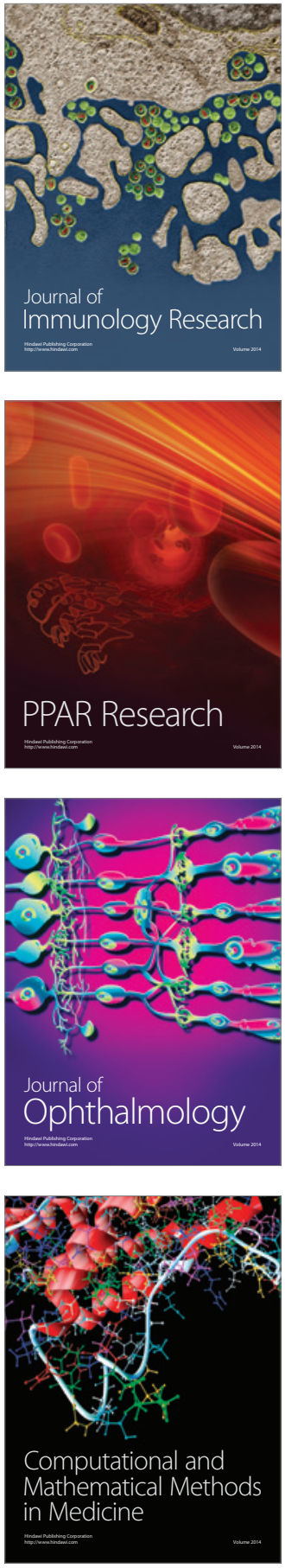

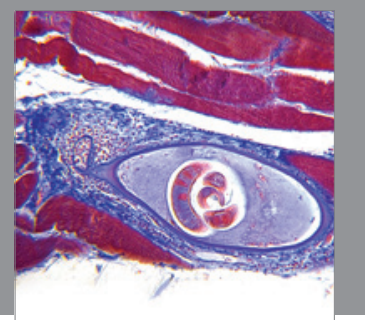

Gastroenterology

Research and Practice
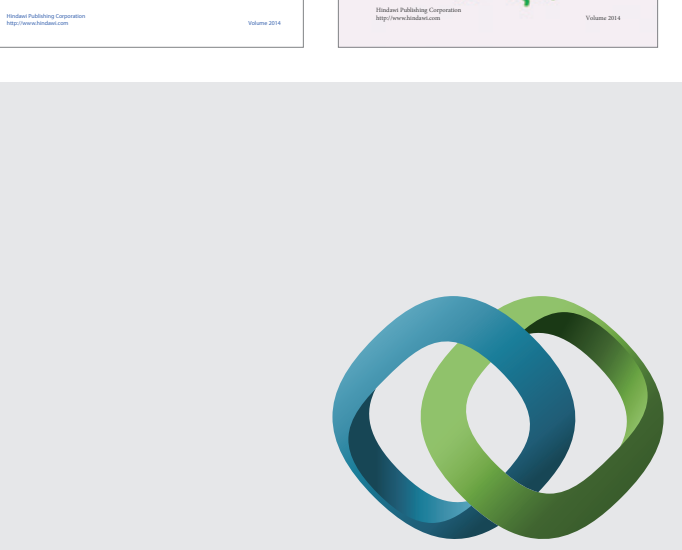

\section{Hindawi}

Submit your manuscripts at

http://www.hindawi.com
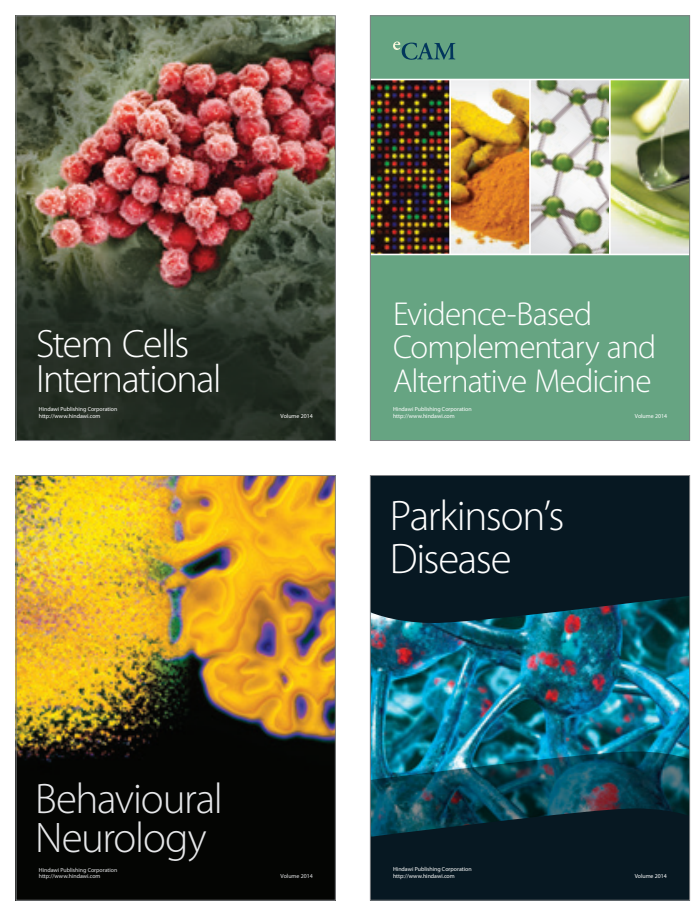

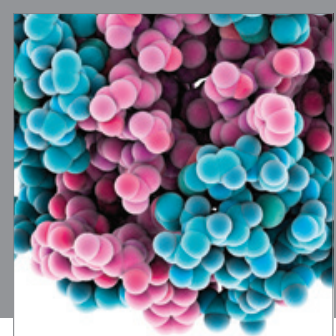

Journal of
Diabetes Research

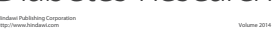

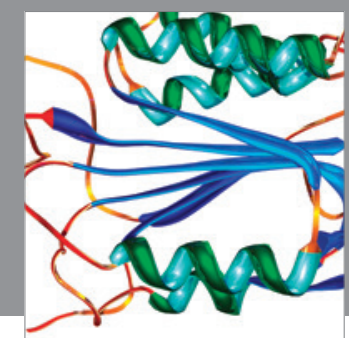

Disease Markers
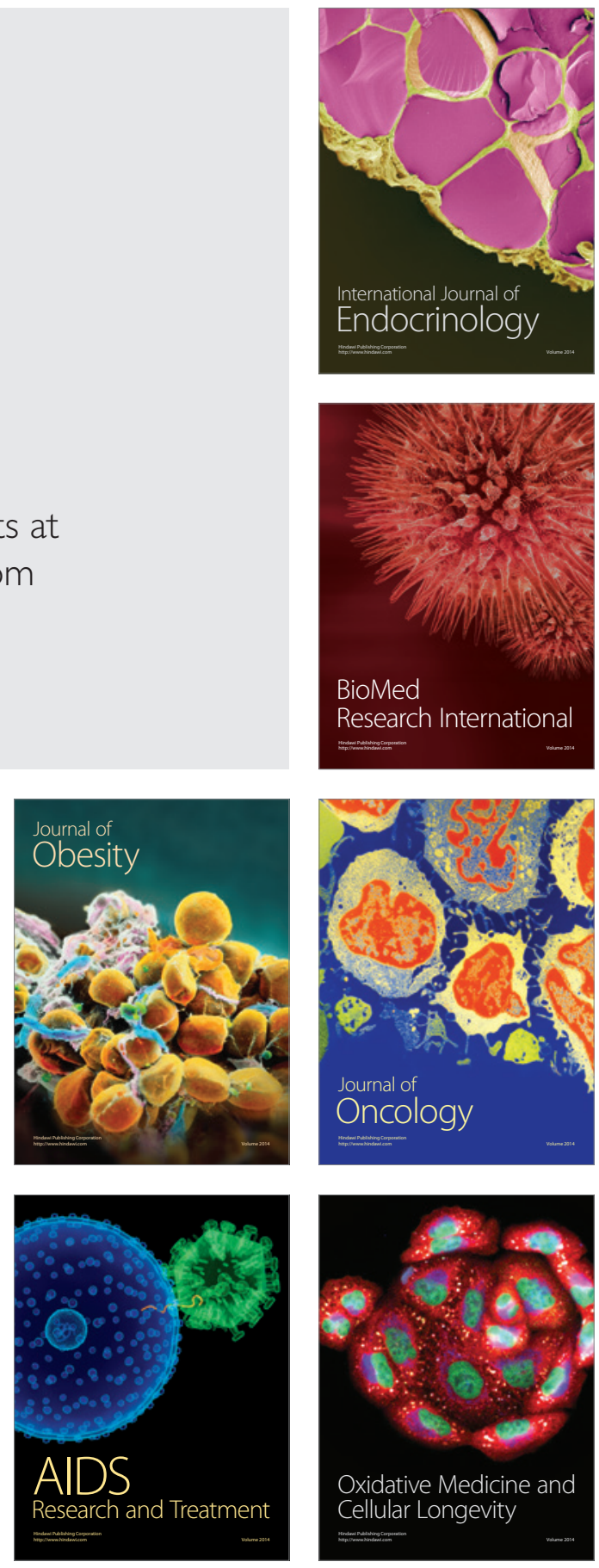